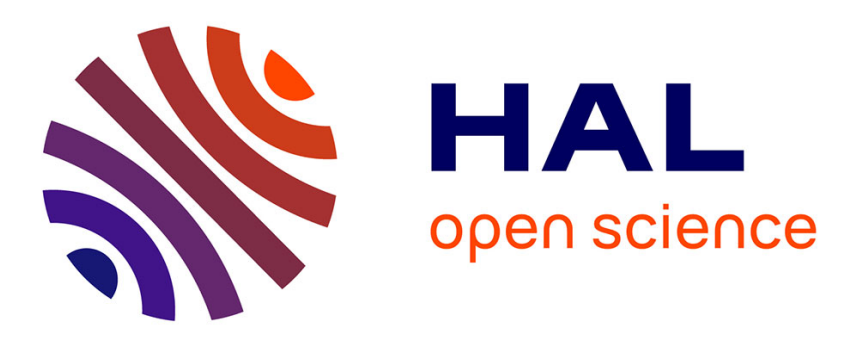

\title{
Characterization of microstructure and texture of binary Mg-Ce alloy processed by equal channel angular pressing
}

Salaheddine Sadi, Abdelkader Hanna, Hiba Azzeddine, Casimir Casas, Thierry Baudin, Anne-Laure Helbert, François Brisset, Jose Maria Cabrera

\section{- To cite this version:}

Salaheddine Sadi, Abdelkader Hanna, Hiba Azzeddine, Casimir Casas, Thierry Baudin, et al.. Characterization of microstructure and texture of binary $\mathrm{Mg}$-Ce alloy processed by equal channel angular pressing. Materials Characterization, 2021, 181, pp.111454. 10.1016/j.matchar.2021.111454 . hal03413879

\author{
HAL Id: hal-03413879 \\ https://hal.science/hal-03413879
}

Submitted on 4 Nov 2021

HAL is a multi-disciplinary open access archive for the deposit and dissemination of scientific research documents, whether they are published or not. The documents may come from teaching and research institutions in France or abroad, or from public or private research centers.
L'archive ouverte pluridisciplinaire HAL, est destinée au dépôt et à la diffusion de documents scientifiques de niveau recherche, publiés ou non, émanant des établissements d'enseignement et de recherche français ou étrangers, des laboratoires publics ou privés. 


\title{
Characterization of microstructure and texture of binary Mg-Ce alloy processed by Equal Channel Angular Pressing
}

Salaheddine Sadi ${ }^{1}$, Abdelkader Hanna $^{2}$, Hiba Azzeddine ${ }^{2 *}$, Casimir Casas $^{3}$, Thierry Baudin ${ }^{4}$, Anne-Laure Helbert ${ }^{4}$, François Brisset ${ }^{4}$ and Jose Maria Cabrera ${ }^{3}$

1 Physics and Chemistry of Materials Laboratory, Department of Physics, University of Mohamed Boudiaf, M'sila, 28000, Algeria.

${ }^{2}$ Laboratoire Matériaux et Energies renouvelables, Faculté des Sciences, Université Mohamed Boudiaf, M'sila, 28000, Algérie.

${ }^{3}$ Department of Materials Science and Engineering, Technical University of Catalonia, 08019Barcelona, Spain.

${ }^{4}$ Université Paris-Saclay, CNRS, Institut de chimie moléculaire et des matériaux d'Orsay, 91405, Orsay, France.

* Corresponding author : Pr. Hiba Azzeddine, email: hiba.azzeddine@univ-msila.dz

\begin{abstract}
The characterization of microstructure and texture development of binary $\mathrm{Mg}-0.3 \mathrm{Ce}$ (wt.\%) after equal-channel angular pressing (ECAP) processing via route $B c$ at 300 and $350{ }^{\circ} \mathrm{C}$ through 4 passes were investigated using electron backscatter diffraction (EBSD) measurements. The results demonstrated an effective grain refinement from millimeter range to 6.7 and $8.3 \mu \mathrm{m}$ obtained after 4 passes at 300 and $350{ }^{\circ} \mathrm{C}$, respectively. The grain refinement was obtained through dynamic recrystallization (DRX). At $300^{\circ} \mathrm{C}$, DRX occurred at low strain by twininduced dynamic recrystallization (TDRX) and particle stimulated nucleation (PSN) mechanism and then converted with increasing strain to sub-grain development (SD) and grain boundary bulging dynamic recrystallization (GBBDRX). Besides, grain growth occurred during processing at $350{ }^{\circ} \mathrm{C}$. The texture development strongly depends on the strain level, deformation temperature and DRX mechanisms. At $300{ }^{\circ} \mathrm{C}$, a typical basal texture with a deviation of $40^{\circ}$ toward extrusion direction was formed gradually up to 4 passes while a completely different texture was formed at $350{ }^{\circ} \mathrm{C}$ due to the large grain size.
\end{abstract}

Keywords: Dynamic recrystallization, Equal channel angular pressing, Magnesium, rare earth, texture, precipitate free zone. 


\section{Introduction}

One of the excellent characteristics of magnesium $(\mathrm{Mg})$ is the lightweight which is a key solution for reducing global warming and environmental pollution in the transportation industries [1]. Nevertheless, the lack of a sufficient number of slip systems caused by the hexagonal (hcp) crystal structure of Mg-based alloys limit their formability at low deformation processing and currently restricts their use in various industries [2].

Over the last decades, grain refinement and texture modification through applying thermomechanical processing or alloying addition elements are considered the crucial features for improving the mechanical properties of Mg-based alloys [3-12].

Severe plastic deformation (SPD) techniques such as equal channel angular pressing (ECAP) have proven their efficiency in producing ultrafine-grained microstructure down to the sub-micrometer level in several Mg-based alloys [3, 5, 11, 12]. Despite the high stacking fault energy $\left(\gamma_{\mathrm{SFE}}=125 \mathrm{~mJ} / \mathrm{m}^{2}\right)$ of $\mathrm{Mg}$, dynamic recrystallization (DRX) is the main mechanism for grain refinement in Mg-based alloys due to the limited number of slip systems [13]. Besides, the $\mathrm{Mg}$ low melting point $\left(\mathrm{T}_{\mathrm{m}}=650{ }^{\circ} \mathrm{C}\right)$ and its relatively low recrystallization temperature $\left(0.5 \mathrm{~T}_{\mathrm{m}}\right)$ promote the occurrence of DRX during hot processing.

However, experimental reports show that ECAP processing parameters like type of route, deformation temperature, number of passes and die geometry greatly influence the final microstructure, texture development, and mechanical properties [14-20]. For example, route $\mathrm{B}_{\mathrm{C}}$, in which the sample is rotated by $90^{\circ}$ after each pass, is the most effective route for grain refinement [21]. In contrast, increasing deformation temperature and lowering processing rates have a negative effect on grain refinement [5, 20, 22]. Frequently, ECAP processing of $\mathrm{Mg}$ based alloy leads to the development of basal texture where the $c$-axis of the majority of grains are rotated about $40-45^{\circ}$ towards the processing direction [4, 7, 23-28]. Unfortunately, the development of such texture results in poor ductility and causes the deterioration of the yield strength $[11,28]$.

Alloying Mg matrix with Rare Earth (RE) elements has shown a tremendous effect on the texture modification and weakening of basal texture and consequently improving the mechanical properties of the processed Mg-based alloys [6, 29, 30]. This improvement is attributed to the role of RE elements in altering the balance of activation of different slip systems, and slowing down the grain boundaries mobility by solute drag and solution strengthening [31, 32]. Hence, the combination of ECAP processing and RE-containing $\mathrm{Mg}$ alloys may be a great strategy to design new Mg-based alloys with higher mechanical 
performances and consequently open a window to extend their applications in various industries.

In this frame, the main goal of the present study is to characterize the microstructure, grain refinement mechanisms and texture development in a binary $\mathrm{Mg}-0.3 \mathrm{Ce}$ (wt.\%) alloy after ECAP processing at 300 and $350^{\circ} \mathrm{C}$ for 1,2 , and 4 passes via route $B c$.

\section{Experimental procedure}

The binary $\mathrm{Mg}-0.3 \mathrm{Ce}$ (wt.\%) alloy used in the present investigation was kindly provided from Institute for Physical Metallurgy and Materials Physics, RWTH Aachen University, Germany. The as-cast alloy preparation was described previously in ref. [33]. Before deformation, the as-cast alloy was homogenized at $420{ }^{\circ} \mathrm{C}$ for $20 \mathrm{~h}$.

Cylindrical samples with $10 \mathrm{~mm}$ in diameter and $55 \mathrm{~mm}$ in length were machined to be deformed by ECAP. ECAP processing was conducted at different temperature 150, 250, 300, and $350{ }^{\circ} \mathrm{C}$ using a die having a channel angle of $\Phi=90^{\circ}$ and an outer arc of curvature of $\Psi$ $=37^{\circ}$ as shown in Figure 1 . However, conducting ECAP processing at 150 and $250{ }^{\circ} \mathrm{C}$ caused the fracture featuring of the sample because of the formation of macroscopic cracks resulting from strong localization of shear deformation as also shown in Figure 1. The samples were pressed for 1,2 , and 4 passes at 300 and $350{ }^{\circ} \mathrm{C}$ through route $\mathrm{B}_{\mathrm{C}}$, where the sample was rotated about the longitudinal axis by 90 ० counterclockwise, and the speed of deformation was 0.5 $\mathrm{mm} / \mathrm{s}$. A molybdenum disulfide $\left(\mathrm{MoS}_{2}\right)$ grease was used as a lubricant. The equivalent strain imposed for each pass is about $\varepsilon_{\mathrm{eq}}=0.98$ according to the following equation [34]:

$$
\varepsilon_{e q}=\frac{N}{\sqrt{3}}\left[2 \cot \left(\frac{\Phi+\psi}{2}\right)+\psi \csc \left(\frac{\Phi+\psi}{2}\right)\right]
$$

where $N$ is the number of ECAP passes 


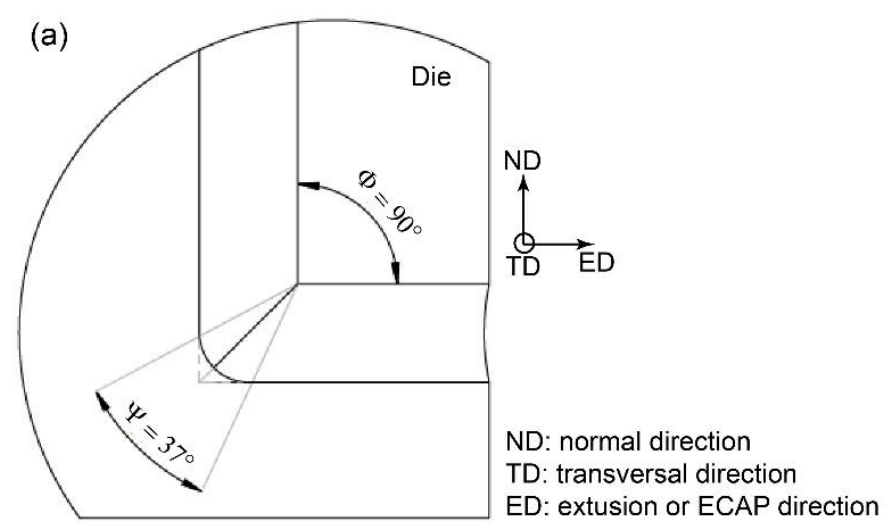

(b) ECAP at $150^{\circ} \mathrm{C}$

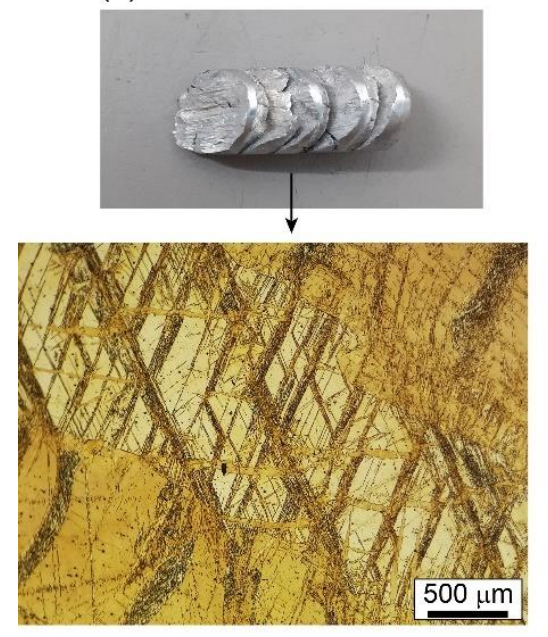

(c) ECAP at $250^{\circ} \mathrm{C}$

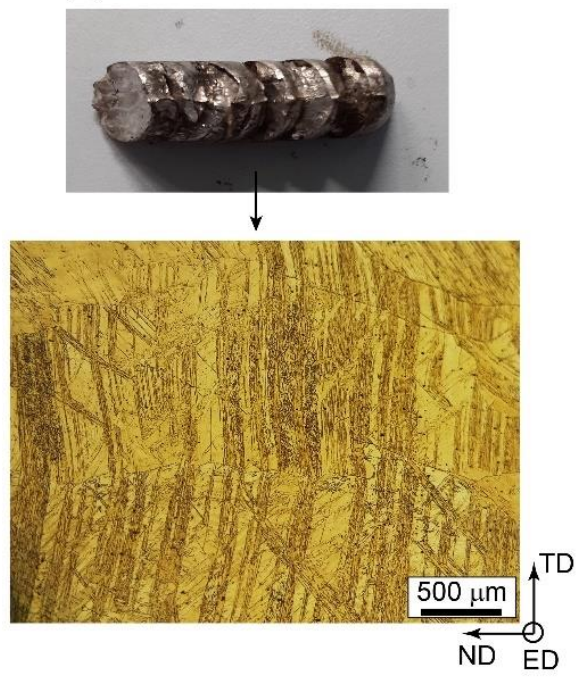

Figure 1: (a) Schematics of ECAP die with reference axes. Photo and microstructure of fractured sample after 1 pass at (b) $150{ }^{\circ} \mathrm{C}$ and (c) $250{ }^{\circ} \mathrm{C}$.

Optical micrography was used to visualize the microstructure of the samples in the TDND plane. The preparation consists of grinding with progressively finer SiC paper followed by electropolishing with 5:3-part ethanol and phosphoric acid for 30 min under 3V-applied voltage and then etching for $3 \mathrm{~s}$ at room temperature in an acetic-nital solution $\left(5 \% \mathrm{HNO}_{3}, 15 \%\right.$ acetic acid, $20 \%$ distilled water, and $60 \%$ ethanol).

EBSD measurements were carried out using a scanning electron microscope FEG-SEM SUPRA $55 \mathrm{VP}$ operating at $20 \mathrm{kV}$ in the TD-ND plane of the samples. The scanned areas were $100 \times 100 \mu \mathrm{m}^{2}$ with a step size of $0.1 \mu \mathrm{m}$ for the all-processed samples. To better investigate the microstructural evolution, EBSD measurements were also performed at smaller step sizes $\left(100 \times 70 \mu \mathrm{m}^{2}\right.$ with a step size of $50 \mathrm{~nm}$ and $30 \times 14 \mu \mathrm{m}^{2}$ with a step size of $\left.20 \mathrm{~nm}\right)$ for sample processed at $300{ }^{\circ} \mathrm{C}$ for 1 pass. The EBSD data analyses were undertaken using the TSL Orientation Imaging Microscopy $\left(\mathrm{OIM}^{\mathrm{TM}}\right)$ software. The grain size data were measured using 
a grain tolerance angle of $5^{\circ}$ and a minimum grain size of 5 pixels. The texture evolution was characterized using the MTEX toolbox [35].

Vickers microhardness was measured in the TD-ND plane using a SHIMADZU type HMV-tester. An average microhardness value was obtained using at least nine indentations under a load of $100 \mathrm{~g}\left(\mathrm{Hv}_{0.1}\right)$ with a dwell time of $10 \mathrm{~s}$.

\section{Results and discussion}

\subsection{Initial state before ECAP processing}

The initial microstructure of the $\mathrm{Mg}-0.3 \mathrm{Ce}$ alloy exhibits a typical as-cast microstructure with large grains $(\sim 1 \mathrm{~mm})$ containing second phases distributed in straight lines as shown by arrows in Figure 2a. Similar second phase morphology has been reported in $\mathrm{Mg}$ $\mathrm{xCe}(\mathrm{x}=0.5,1$ and 2, wt.\%) alloy [36]. The thickness of these second-line particles increases with increasing Ce element [36]. The identification of this phase was not possible due to their smallness but based on the phase diagram they can be associated to the $\mathrm{Mg}_{12} \mathrm{Ce}$ phase [36] Other particles (in white) were also observed in SEM micrography (point 1) containing about 9.2 wt. $\%$ of Ce.

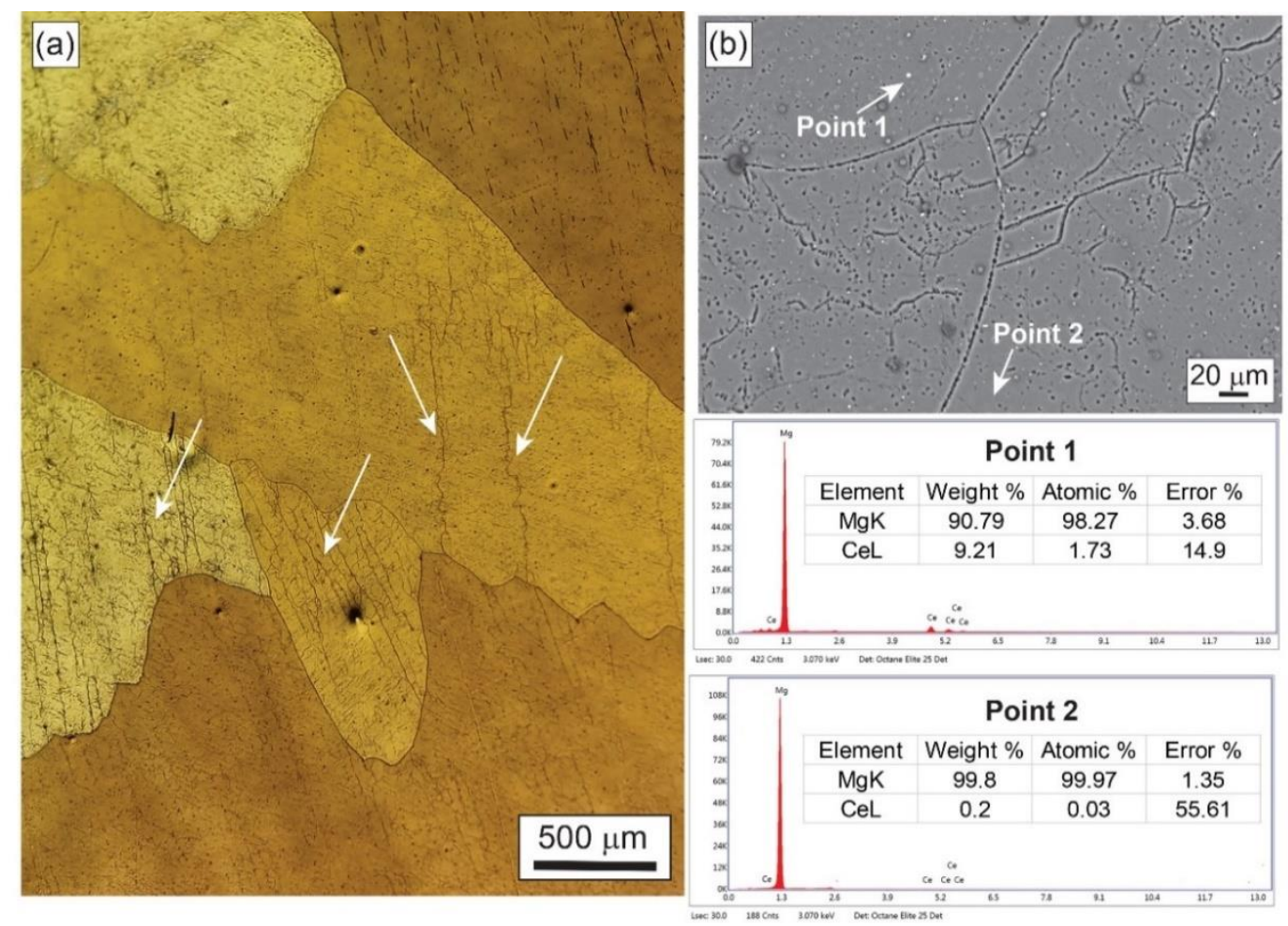

Figure 2: (a) Optical micrography and (b) SEM micrography with EDS analyses of the initial state of the current $\mathrm{Mg}-0.3 \mathrm{Ce}$ alloy. 


\subsection{Microstructural evolution after ECAP processing}

Figure 3 shows the evolution of the microstructure obtained by optical micrography of the $\mathrm{Mg}-0.3 \mathrm{Ce}$ alloy after ECAP processing at 300 and $350{ }^{\circ} \mathrm{C}$ after 1,2 , and 4 passes, respectively. Dynamic precipitation occurred during ECAP processing and it was more pronounced in samples processed at $300{ }^{\circ} \mathrm{C}$, while small grains were developed in samples processed at $350{ }^{\circ} \mathrm{C}$ soon after 1 pass resulting from dynamic recrystallization (DRX).
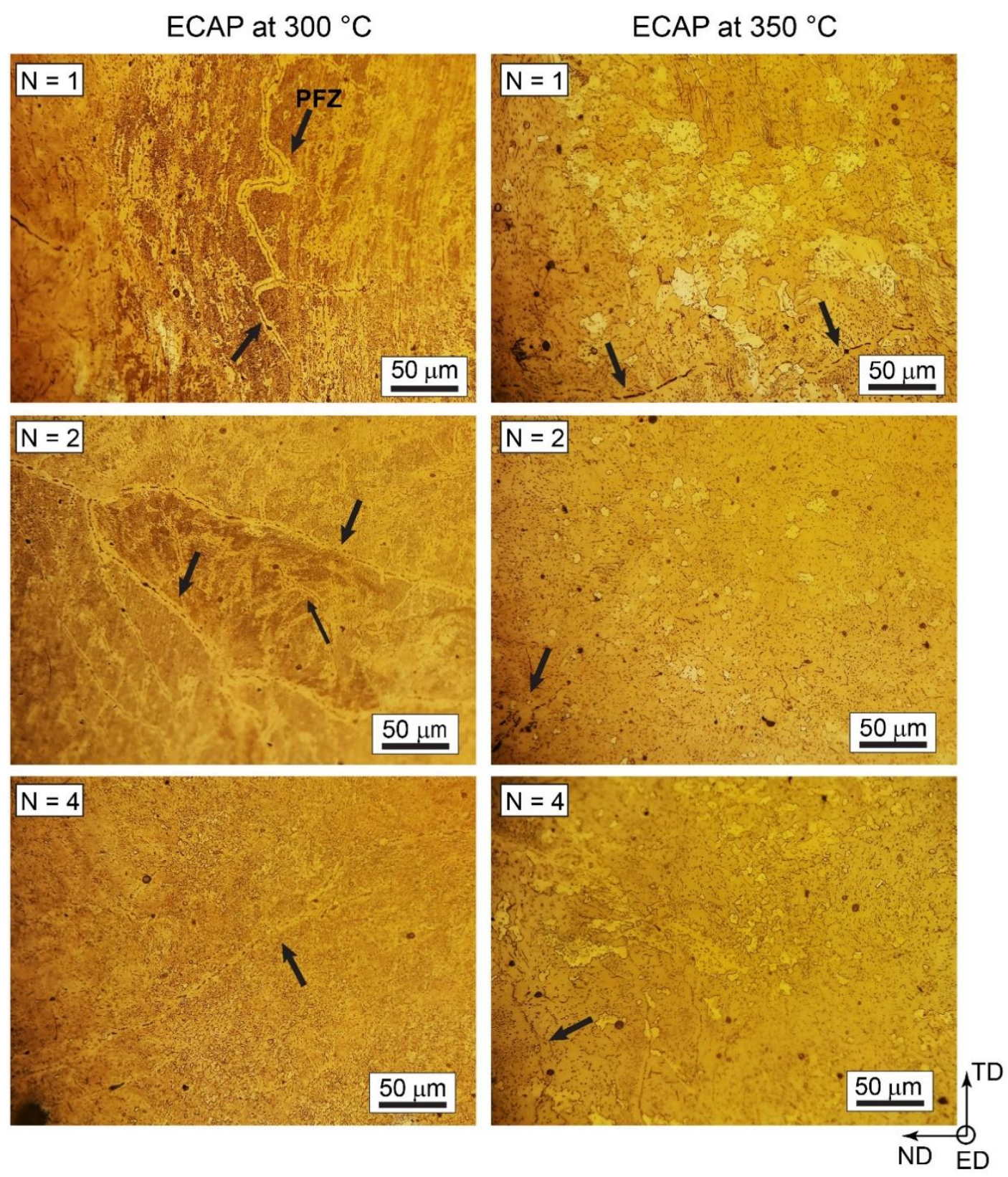

Figure 3: Optical micrographics of the present $\mathrm{Mg}-0.3 \mathrm{Ce}$ alloy after ECAP processing at 300 and $350{ }^{\circ} \mathrm{C}$ after 1,2 and 4 passes, respectively. Arrows indicate Precipitation Free Zones (PFZ). 
It can be noticed from the microstructural comparison of both processing conditions (at 300 and $350{ }^{\circ} \mathrm{C}$ ) that DRX is retarded or inhibited by dynamic precipitation during ECAP at $300{ }^{\circ} \mathrm{C}$. Similar observations have been reported for WE54 (Mg-5Y-4Nd-0.5Zr, wt.\%) alloy processed by uniaxial and plane strain compression at $300{ }^{\circ} \mathrm{C}$ under a strain rate of $10^{-4} \mathrm{~s}^{-1}[30]$ and in ECAP-processed AZ91 (Mg-9Al-1Zn, wt.\%) at $300{ }^{\circ} \mathrm{C}$ through 4 passes [37]. In this case, the precipitate particles act as a barrier to the grain boundaries migration through a pinning effect $[30,37]$.

It is interesting to note that precipitates free zones (PFZ) were formed along grain boundaries and stable second particle areas in form of straight lines as shown by arrows in Figure 3. The PFZ are widely reported in Al-based alloys [38-42] but rarely in Mg-based alloys $[43,44]$. Several mechanisms have been proposed to explain the formation of PFZ such as vacancy depletion [45, 46], solute depletion [47, 48], and the dissolution of Guinier-Preston (GP) zones [39]. The vacancy depletion does not seem an accurate reason for the formation of PFZ in the present case since it is well known that ECAP processing can introduce a high density of defects. The precipitation sequence reported for $\mathrm{Mg}$-Ce solid solution can be described as $\mathrm{Mg}$ supersaturated solution $\rightarrow$ GP-zone $\rightarrow \beta_{1}\left(\mathrm{Mg}_{3} \mathrm{Ce}\right) \rightarrow \beta\left(\mathrm{Mg}_{12} \mathrm{Ce}\right)$ [49]. Hence, it can be suggested that the solute and dissolution of the GP zone are the main mechanisms responsible for the formation of PFZ in the present alloy. However, Figure 4 shows that the PFZ width decreases with the increasing number of ECAP passes and the decreasing deformation temperature. The PFZ width was defined here as the distance of the denuded zone along both side of the grain boundary [41].

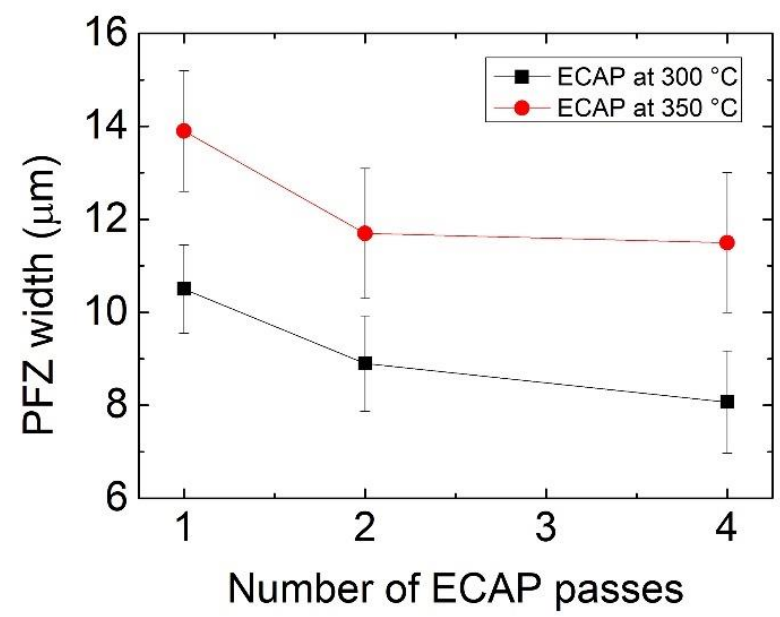

Figure 4: Evolution of PFZ width as a function of the number of ECAP passes of the Mg$0.3 \mathrm{Ce}$ alloy processed at 300 and $350{ }^{\circ} \mathrm{C}$, respectively. 
The PFZ width decreases with increasing strain indicating that precipitation is enhanced during ECAP processing due to the accumulation of defects such as dislocations near the grain boundaries. It was found also that the PFZ width decreases with decreasing grain size in $\mathrm{Mg}$ 8Al-0.5Zn alloy [43]. It is worth noting that the PFZ width reported in Mg-8Al-0.5Zn alloy (in the range of $0.4-0.6 \mu \mathrm{m}$ ) was much smaller than those obtained in the present alloy (in the range of 8-14 $\mu \mathrm{m})$. The alloying elements play a significant role in the formation of PFZ and their width [40]. The PFZ width is larger in samples processed at $350{ }^{\circ} \mathrm{C}$ than at $300{ }^{\circ} \mathrm{C}$ which confirms that dynamic precipitation is less pronounced in samples processed at $350{ }^{\circ} \mathrm{C}$. The occurrence of DRX in samples processed at $350{ }^{\circ} \mathrm{C}$ may also influence the PFZ width.

To further investigate the effect of DRX on the microstructural evolution of the current ECAP processed $\mathrm{Mg}-0.3 \mathrm{Ce}$ alloy, Figures 5 and 6 show the orientation imaging micrography (OIM) in inverse pole figure (IPF) maps at 300 and $350{ }^{\circ} \mathrm{C}$ after1, 2 and 4 ECAP passes, respectively. The black and white lines indicate high angle boundaries (HAGBs) with misorientation $>15^{\circ}$ and low angle boundaries (LAGBs) with misorientation between 5 and $15^{\circ}$, respectively. The average grain size is shown in the upper side of the IPF maps. 

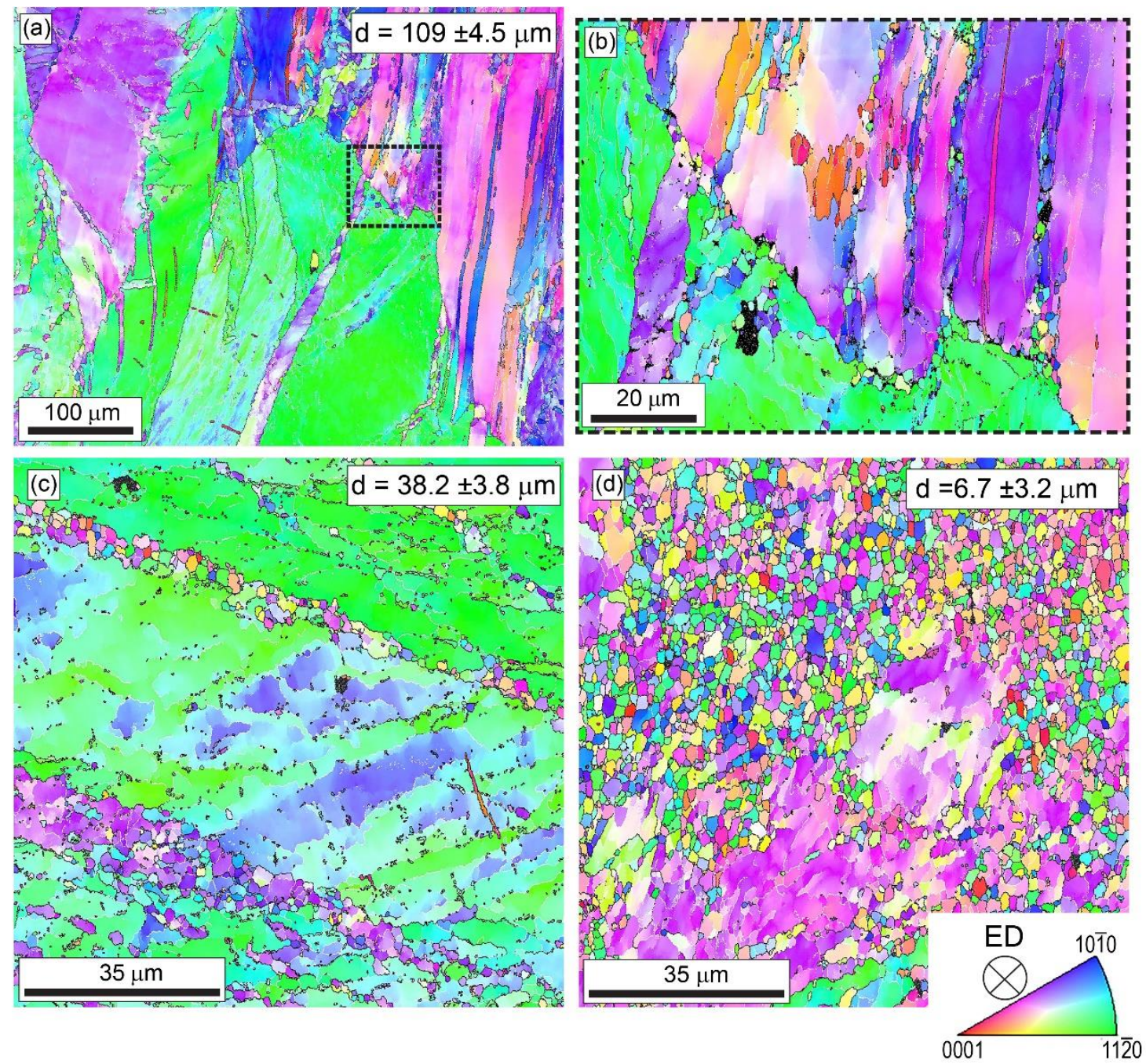

Figure 5: ED-IPF maps showing the microstructure of the $\mathrm{Mg}-0.3 \mathrm{Ce}$ alloy after ECAP processing at $300{ }^{\circ} \mathrm{C}$ through: (a, b) 1 pass with low and high magnification, respectively, c) 2 passes and d) 4 passes.

For both deformation temperatures, it is obvious that the microstructure after 1 and 2 passes is very heterogeneous. After 1 pass at $300^{\circ} \mathrm{C}$, the microstructure is still containing large grains but with the presence of extensive LAGBs and several deformation features such as twins. After 2 ECAP passes a different microstructure is noticed in which a typical bimodal grain structure is formed, with elongated deformed grains surrounded by fine equiaxed grains in a necklace-like form resulting from DRX (Figure 5c).

It can be suggested that the beginning of deformation is controlled by mechanical twinning and then changes to slip deformation with increasing strain. Figure 6a demonstrated that mechanical twinning is absent in the microstructure of the sample processed for 1 pass at 
$350{ }^{\circ} \mathrm{C}$. It is well known that the activation of the non-basal slip systems increases with increasing deformation temperature which makes mechanical twinning inactive. It is expected that the change in deformation mechanisms causes a change in the nucleation mechanisms of DRX
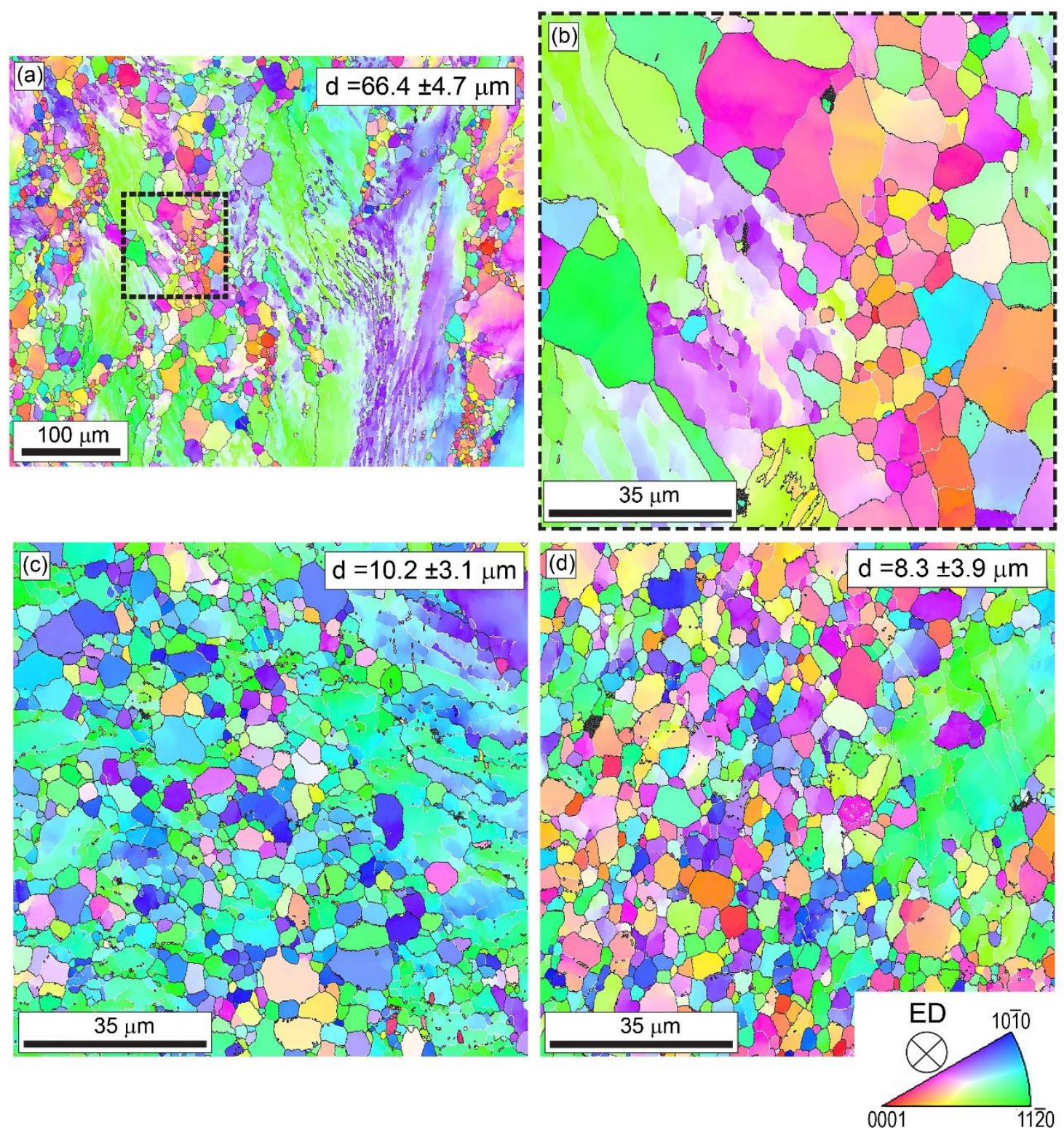

Figure 6: ED-IPF map showing the microstructure of the $\mathrm{Mg}-0.3 \mathrm{Ce}$ alloy after ECAP processing at $350{ }^{\circ} \mathrm{C}$ through: (a, b) 1 pass with low and high magnification, respectively, c) 2 passes and d) 4 passes.

After 4 passes more homogenous microstructure can be observed with the decrease of elongated deformed grains and formation of finer equiaxed grains. The formation of the fine microstructure is faster after processing at $350{ }^{\circ} \mathrm{C}$ due to the increase of the dynamic 
recrystallization rate. Very effective grain refinement is obtained after 4 passes where the grain size decreases from millimeter range at the initial state to 6.7 and $8.3 \mu \mathrm{m}$ at deformation processing of 300 and $350{ }^{\circ} \mathrm{C}$, respectively. However, a uniform grain size distribution is not yet achieved for both conditions. Thus, the development of a homogenous microstructure in the present $\mathrm{Mg}-0.3 \mathrm{Ce}$ alloy might involve more ECAP passes.

Even with an as-cast and coarse initial microstructure which is not currently used in the literature for ECAP processing, the present investigation shows that the ECAP processing of the present as-cast $\mathrm{Mg}-0.3 \mathrm{Ce}$ alloy results in very good grain refinement compared to another Mg-based alloys. This excellent grain refinement has not been obtained in conventional $\mathrm{Mg}$ Al based alloys such AZ31 and AZ61 (Mg-6Al-1Zn, wt.\%) alloys [50-53], or in Mg-Zn-CaMn alloy [54] and Mg-13Gd-4Y-2Zn-0.6Zr (wt.\%) alloys [55] under similar ECAP processing conditions (i.e. ECAP via route $\mathrm{Bc}$ through 4 passes). For example, on one hand, two AZ31 alloys with an initial grain size of $390 \mu \mathrm{m}$ [50] and $48 \mu \mathrm{m}$ [51] were refined to $3.5 \mu \mathrm{m}$ and 3.9 $\mu \mathrm{m}$ after 4 passes at 250 and $240^{\circ} \mathrm{C}$, respectively. On the other hand, the grain size of an AZ61 alloy decreased from $\sim 60 \mu \mathrm{m}$ to $\sim 20 \mu \mathrm{m}$ after 4 passes at $300{ }^{\circ} \mathrm{C}$ [53]. Besides, the reported investigations show that multi-step ECAP with gradually decreasing processing temperature promotes further grain refinement down to $\sim 250 \mathrm{~nm}[3,5,11]$.

The recrystallized grains can be separated from the deformed ones by using the grain orientation spread (GOS) approach [56]. GOS is defined as the mean standard deviation of all the orientations inside the grain and usually, recrystallized grains in Mg-based alloys have GOS values less than $2^{\circ}[56,57]$. As shown in Figure 7 , the fraction of recrystallized grains increases with the increasing number of ECAP passes and deformation temperature. It can be noticed that the fraction of DRX continuously increases up to 4 passes in the case of samples processed at $300{ }^{\circ} \mathrm{C}$ while the fraction of DRX of sample processed at $350{ }^{\circ} \mathrm{C}$ increases rapidly after 2 passes $(51.3 \%)$ and then slowly increased to $57.8 \%$ after 4 passes. However, a relatively similar fraction of DRX is formed for samples processed through 4 passes at both temperatures ( $55 \%$ at $300{ }^{\circ} \mathrm{C}$ and $\sim 58 \%$ at $350{ }^{\circ} \mathrm{C}$, respectively). This similarity confirms that the effect of dynamic precipitation is less pronounced at high strain. However, DRX is extremely retarded in the present alloy compared to the ECAP processed AZ91 (Mg-9Al-1Zn, wt.\%) alloy under similar conditions (i.e. ECAP at $310{ }^{\circ} \mathrm{C}$ through $1-4$ passes via route $\mathrm{B}_{\mathrm{c}}$ ) and undergoing dynamic precipitation of $\mathrm{Mg}_{17} \mathrm{Al}_{12}$ in which the fraction of DRX increased from $39 \%$ after 1 pass up to $77 \%$ after 4 passes [37]. Recently, it was found that the binary Mg-0.4Dy (wt.\%) 
alloy shows retardation of DRX during plane strain compression test even at $400{ }^{\circ} \mathrm{C}$ under strain rate of $10^{-4} \mathrm{~s}^{-1}$ where a complete DRX is often reported in Mg-based alloys [30, 57-59].
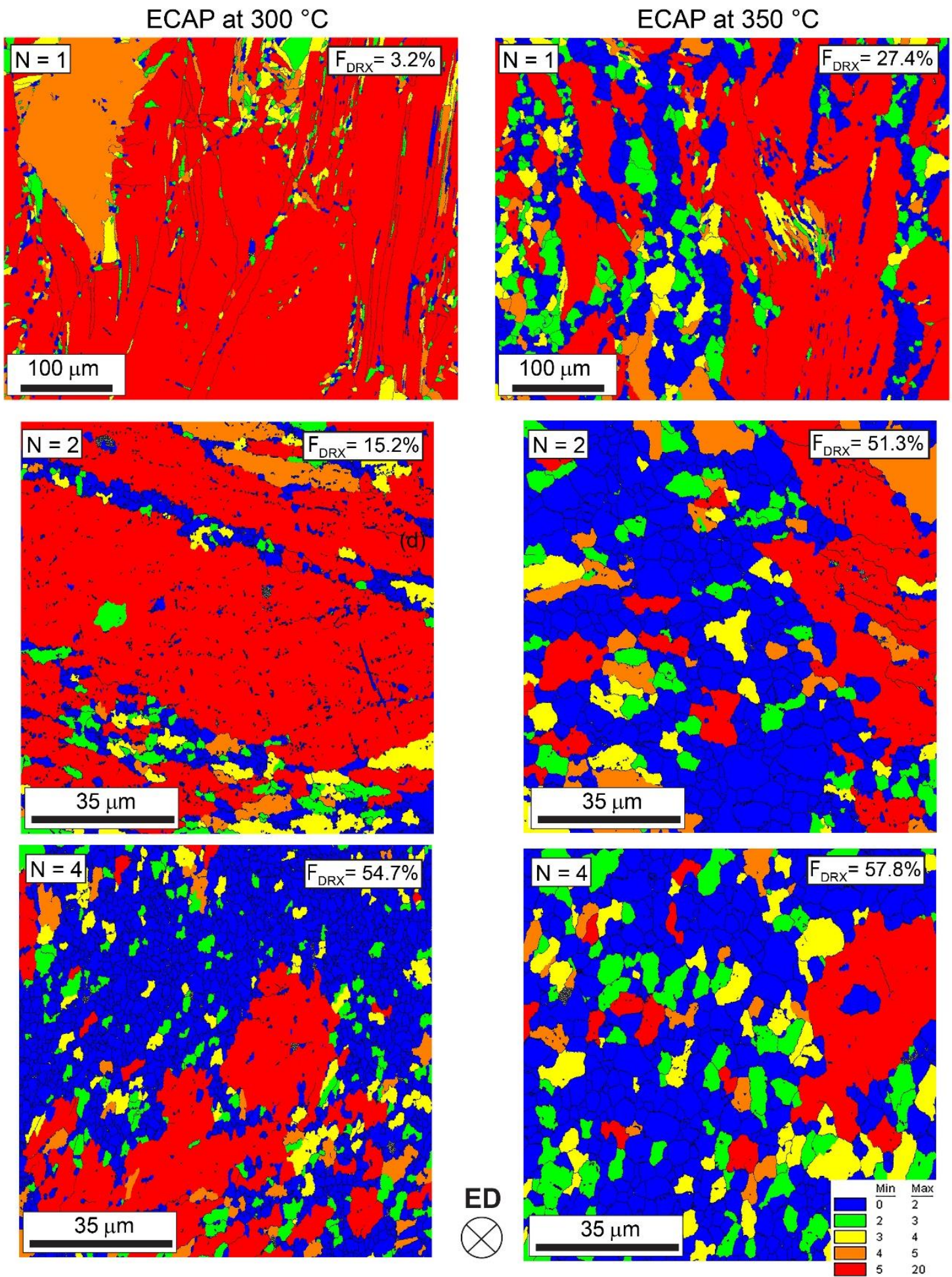

Figure 7: GOS maps of the Mg-0.3Ce alloy processed by ECAP at 300 (left hand side column) and $350^{\circ} \mathrm{C}$ (right hand side column) through 1,2 and 4 passes, respectively. 
This behavior has been explained by the fact that the activation of non-basal slip systems such as $<c+a>$ pyramidal slip system is easy during deformation in Mg-RE alloys and in this case DRX is not needed to accommodate the deformation [57]. Indeed, it has been recently reported that the pyramidal $<\mathrm{c}+\mathrm{a}>$ slip system is the main deformation mode responsible for the accommodation of deformation at room temperature in $\mathrm{Mg}-0.5 \mathrm{Ce}$ (wt.\%) alloys [60]. Moreover, the RE solute segregation at grain boundaries strongly delays DRX by suppressing the mobility of grain boundaries [61].

Figure 8 presents the evolution of recrystallized grains size as a function of the number of ECAP passes for both deformation temperatures. The recrystallized grain size decreases with the increasing number of ECAP passes for both conditions and then seems to stabilize up to 4 passes around 2.0 and $4.3 \mu \mathrm{m}$ at 300 and $350{ }^{\circ} \mathrm{C}$, respectively. The recrystallized grain size increases with the increasing deformation temperature. Indeed, increasing deformation temperatures led to the continuous growth of the rate of DRX and the increase of the grain boundary migration rate [62-64]. It worth mentioning that taking out the processed sample from the die during the ECAP process takes time, subsequently, it is expected that after DRX some static recrystallization can occur, and also some grain growth.

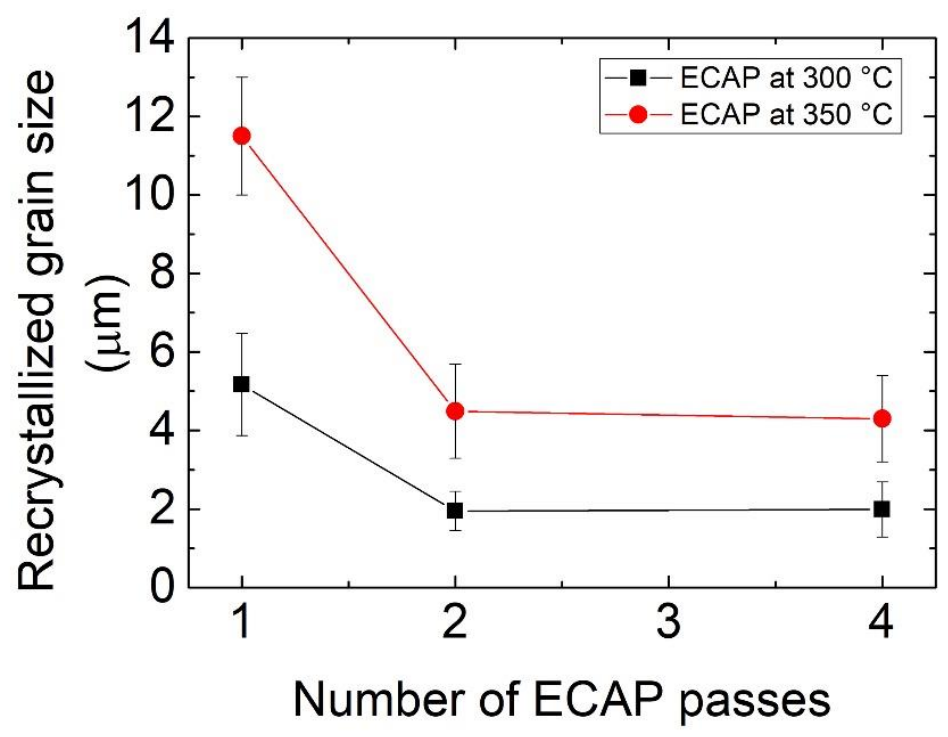

Figure 8: Evolution of the recrystallized grain size as a function of the number of ECAP passes for the $\mathrm{Mg}-0.3 \mathrm{Ce}$ alloy processed at 300 and $350{ }^{\circ} \mathrm{C}$, respectively.

So far, and based on the obtained results, it can be recognized that the optimum temperature for ECAP processing of the current $\mathrm{Mg}-0.3 \mathrm{Ce}$ alloy is $300{ }^{\circ} \mathrm{C}$ since the formability 
was insufficient at lower temperatures $\left(150\right.$ and $\left.250^{\circ} \mathrm{C}\right)$ as shown in Figure 1 and grain growth occurs at a higher temperature $\left(350{ }^{\circ} \mathrm{C}\right)$.

Interesting to note that different DRX mechanisms were observed in the present ECAPprocessed $\mathrm{Mg}-0.3 \mathrm{Ce}$ alloy especially in the early stage of deformation at $300{ }^{\circ} \mathrm{C}(1$ and 2 passes). Figure 9 presents a zoom from the IPF map of the sample processed for 1 pass at $300{ }^{\circ} \mathrm{C}$. The first mechanism was identified as twin-induced dynamic recrystallization (TDRX) where the twins constitute preferred nucleation sites for DRX [65]. The different twins are highlighted in Figure 9b as followed: extension twin $86^{\circ}\langle 11-20\rangle \pm 10^{\circ}$ in green, contraction twin $56^{\circ}\langle 11-20\rangle \pm 10^{\circ}$ (in black), double twins $38^{\circ}\langle 11-20\rangle \pm 10^{\circ}$ (in blue) and $22^{\circ}\langle 11-20\rangle$ $\pm 10^{\circ}$ (in red). The angular deviation from the ideal twin boundaries was chosen $\pm 10^{\circ}$. As can be noticed, twin bands involving contraction and double twins contain several fine grains inside them. The presence of dislocations and their rearrangement inside the twins cause their subdivision into sub-grains and consequently are converted into new grains having HAGBs with further increasing strain [66].

On the contrary, the extension twin in the present alloy seems not to be a preferred site for nucleation of new grains since the extension twin shown in Figure 9a is free of grain and even free from dislocations or LAGBs. This may confirm the observations that extension twins are usually not the preferred site for DRX due to low strain accumulation within them and low mobility of their twin boundaries [67, 68]. It was reported that even during static recrystallization treatement, no new grains nucleation was observed neither at the twin-twin intersections nor at the multiple twin variants of a grain in pure $\mathrm{Mg}[69,70]$.

However, recently, it has been observed that TDRX occurred at extension twins in processed Mg-0.4Dy alloys [57]. As can be seen from the Image Quality (IQ+ED-IPF) map shown in Figure 9a, some fine precipitate particles are distributed inside the extension twin which may carry on a pining effect and prevents the development of dislocations and LAGBs. However, the corresponding $\{0002\}$ pole figures (figure 9c) displaying the orientations of extension twin (ET), twin band (TB) and the parent grains (P) demonstrates that the different mechanical twinning can create new orientations. The dynamically recrystallized grains inside the twins develop a similar orientation to the host twin. In contrast, the intersection of twin along with grain boundaries generates a large number of dynamically recrystallized grains with wide orientations as shown in the yellow box in Figure 9a and in the corresponding $\{0002\}$ pole figure. It can be suggested that the intersection of twin bands with grain boundaries supply an extra driving force of grain nucleation. 


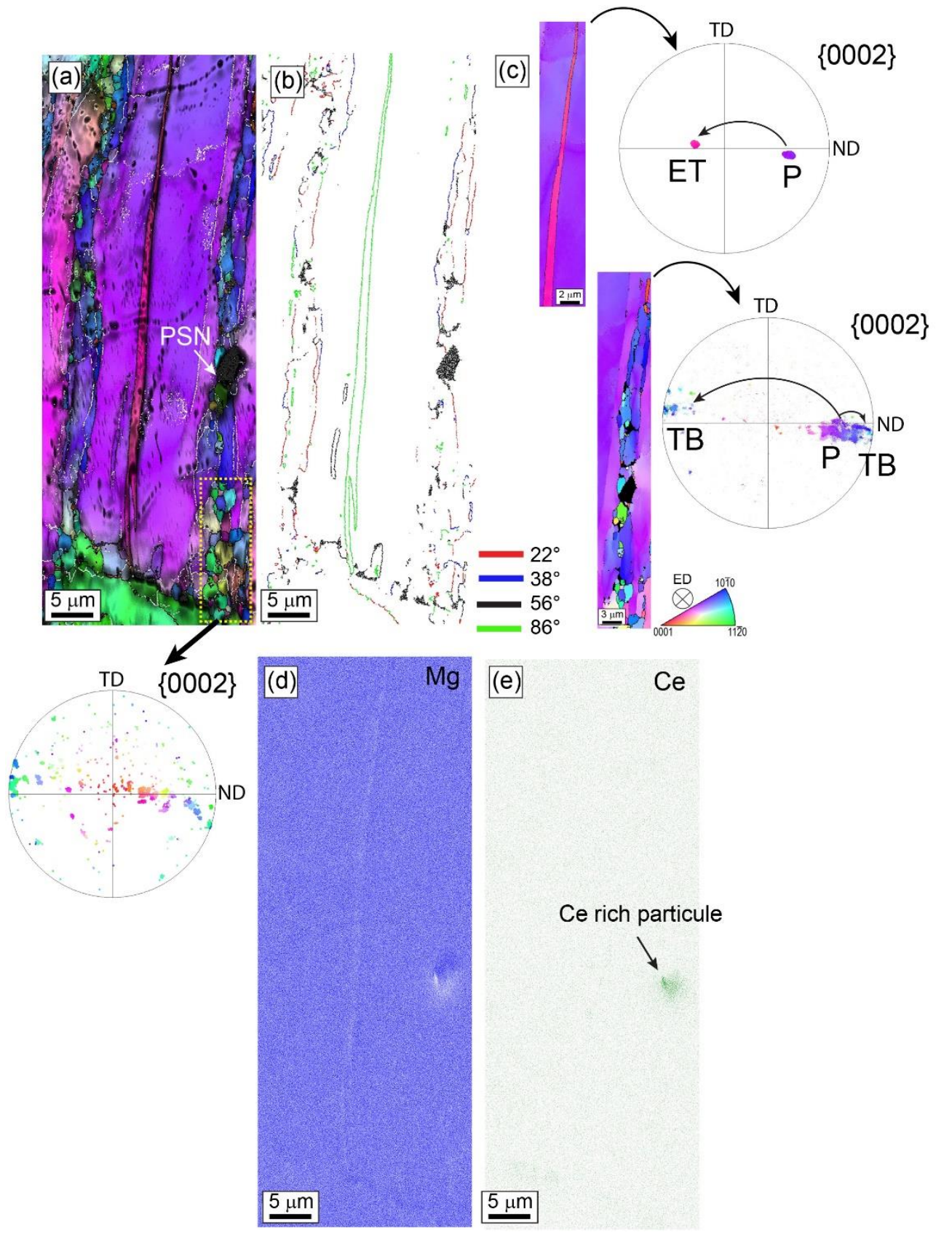


randomly oriented [13]. As can be seen from the $\mathrm{Mg}$ and Ce element mapping (Figures 9d and e) new fine grains with different orientations are formed around a particle rich in Ce element ( $2.5 \mu \mathrm{m}$ of diameter). Surprisingly, this large particle is located nearby the twin band. However, TDRX and PSN mechanisms were only observed after 1 ECAP pass at $300^{\circ} \mathrm{C}$ which led to conclude that such mechanisms can be operating only at low strain and relatively low deformation temperature. Indeed, new recrystallized grains resulted from TDRX could not be recognized with further increasing strain or deformation temperature since twins can grow and ultimately consume the entire parent grain, making them indistinguishable from the original microstructure [71]. On the other hand, PSN was not largely present in the ECAP-processed alloy and seems to have a minor effect on DRX. This is in good agreement with the fact that the occurrence of PSN in Mg-based alloy is more preferred around large particles clustering than in isolated coarse particles (even with an average size larger than $1 \mu \mathrm{m}$ ) [72]. It has been reported that the presence of dynamically developed particles and their pinning effect may offset the PSN at large particles [73] which fits well with the present results. Moreover, it has been noticed that the recrystallized grains by the PSN mechanism cannot subsist during subsequent annealing compared to those formed near the grain boundaries [72].

The ED-IPF map in a selected region near the grain boundary of the same sample (1 pass at $300{ }^{\circ} \mathrm{C}$ ) presented in Figure 10a illustrates a third mechanism which is the grain boundary bulging dynamic recrystallization (GBBDRX) mechanism [74]. As can be seen, the grain boundary is serrated and several new fine grains appear along the initial grain boundary. In this mechanism, the grain boundary bulging between adjacent deformed grains is induced by the grain boundary migration from the low dislocation density side to the high dislocation density side. With further strain, the misorientation between the bulges and deformed grains increases, leading to the transformation of LAGBs into HAGBs, and then the bulged regions become recrystallized grains $[75,76]$. It has been suggested that bulging of the grain boundaries is stimulated when the pyramidal $\langle\mathrm{c}+\mathrm{a}>$ slip system is activated [74]. This mechanism is considered a discontinuous DRX (DDRX) process. It must be noted that the GBBDRX is considered as the main mechanism responsible for new grain formation at high strain $\left(\varepsilon_{\mathrm{eq}}>\right.$ 0.8) in deformed Mg-based alloys [77, 78]. Moreover, the occurrence of the GBBDRX mechanism at medium to high deformation temperature results in new grains having similar orientations to those adjacent grains (parent grains). However, even if the strain is high after 1 pass $\left(\varepsilon_{\mathrm{eq}}=0.9\right)$, the GBBDRX mechanism is not profuse and the orientations of new grains are different from the adjacent grains. This behavior could be attributed to at least two reasons: 1) 
the coarsening of the initial grain size and 2) the presence of precipitate particles along the grain boundaries. Indeed, it has been informed that the migration rate of grain boundaries from the GBBDRX mechanism within coarse grains is very limited [75, 79]. As shown by the IQ+ED-IPF map in Figure 10b, the grain boundary contains precipitate particles. This can suggest that these precipitates could prevent the bulging and the formation of new grains by a pinning effect. Furthermore, the orientations of the new grains are completely different from the adjacent deformed grains. It is believed that the PSN effect tends to occur at grain boundaries.

Figure $10 \mathrm{~b}$ reveals that the formation of new grains can occur in the PFZ adjacent to the grain boundaries and cannot cross the PFZ width (see arrows in Figure 10b). Besides, as indicated in Figure 10b, the PFZ was also formed along with the stable particles and their width is smaller than at grain boundaries. A close inspection of the IQ+ED-IPF map (Figure 10b) indicates that the interior of some fine recrystallized grains contains dynamic precipitates, suggesting a certain competition relationship between dynamic precipitation and DRX.

Figure 10c shows the presence of a fourth mechanism where new grains are starting to form inside the deformed grain. In this case, the LAGBs developed inside the deformed grains by the accumulation of high density of dislocations as known by the sub-grain development (SD) mechanism [75, 80]. The LAGBs gradually transformed to HAGBs by continuous absorbing dislocations which are characteristic of the continuous DRX (CDRX) process [75, 80]. The accumulation of dislocations is confirmed by the kernel average misorientation (KAM) map shown in Figure 10c. Usually, the KAM approach reflects the distribution of strain and the dislocation density, especially the geometrically necessary dislocations (GND) type on individual measurement points [81]. In this case, the KAM map was calculated from the mean misorientation angle between the point and its third neighbors and by excluding misorientations greater than $5^{\circ}$.

Apparently, the SD mechanism allows the generation of new grains with a different orientation than the deformed grains as shown in the corresponding $\{0002\}$ pole figure of this region. Interesting to note that the dislocation accumulation leading to the formation of subgrains $\left(2^{\circ}<\theta<5^{\circ}\right)$ was also formed around particles as shown by arrows in the same region (Figure 10c) involving the PSN mechanism. 

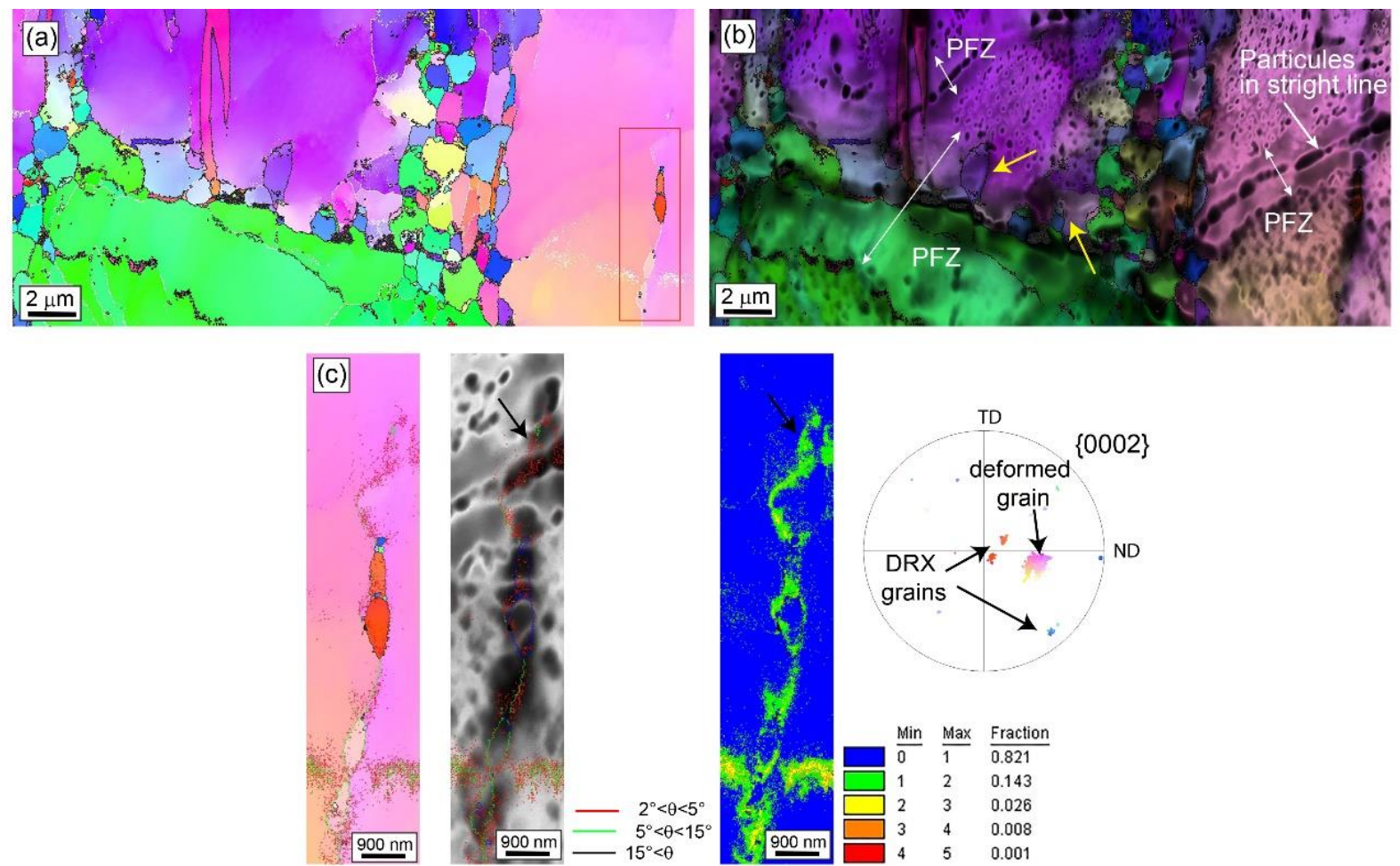

Figure 10: A selected zone from the sample processed at $300{ }^{\circ} \mathrm{C}$ for 1 pass showing GBBDRX and SD mechanisms: (a) ED-IPF map, (b) IQ+ED-IPF map and c) ED-IPF, IQ and KAM maps of the red box zone selected from (a) and the corresponding $\{0002\}$ pole figure.

With further strain, the SD (CDRX) mechanism seems to dominate rather than the GBBDRX (DDRX) mechanism as can be clearly seen in the sample processed for 2 passes at $300{ }^{\circ} \mathrm{C}$ (Figure $3 \mathrm{~b}$ ) and its selected zone shown in Figure 11a. Grains are still large and contain a high fraction of LAGBs which causes the formation of orientation gradient inside them as evidenced by the gradual increase in the misorientation angle profile from points $\mathrm{A}$ to $\mathrm{B}$ and $\mathrm{C}$ to D (Figure 11b). The separated deformed and recrystallized maps presented in Figures $11 \mathrm{c}$ and d show that many new recrystallized grains have different orientations than the deformed grains. The SD mechanism resulted in the development of a necklace structure similar to the GBBDRX (Figure 11c). Moreover, both mechanisms resulted in the development of new orientations. Such a result indicated that CDRX and DDRX mechanisms were concomitantly activated making their separation difficult with further increasing strain. 

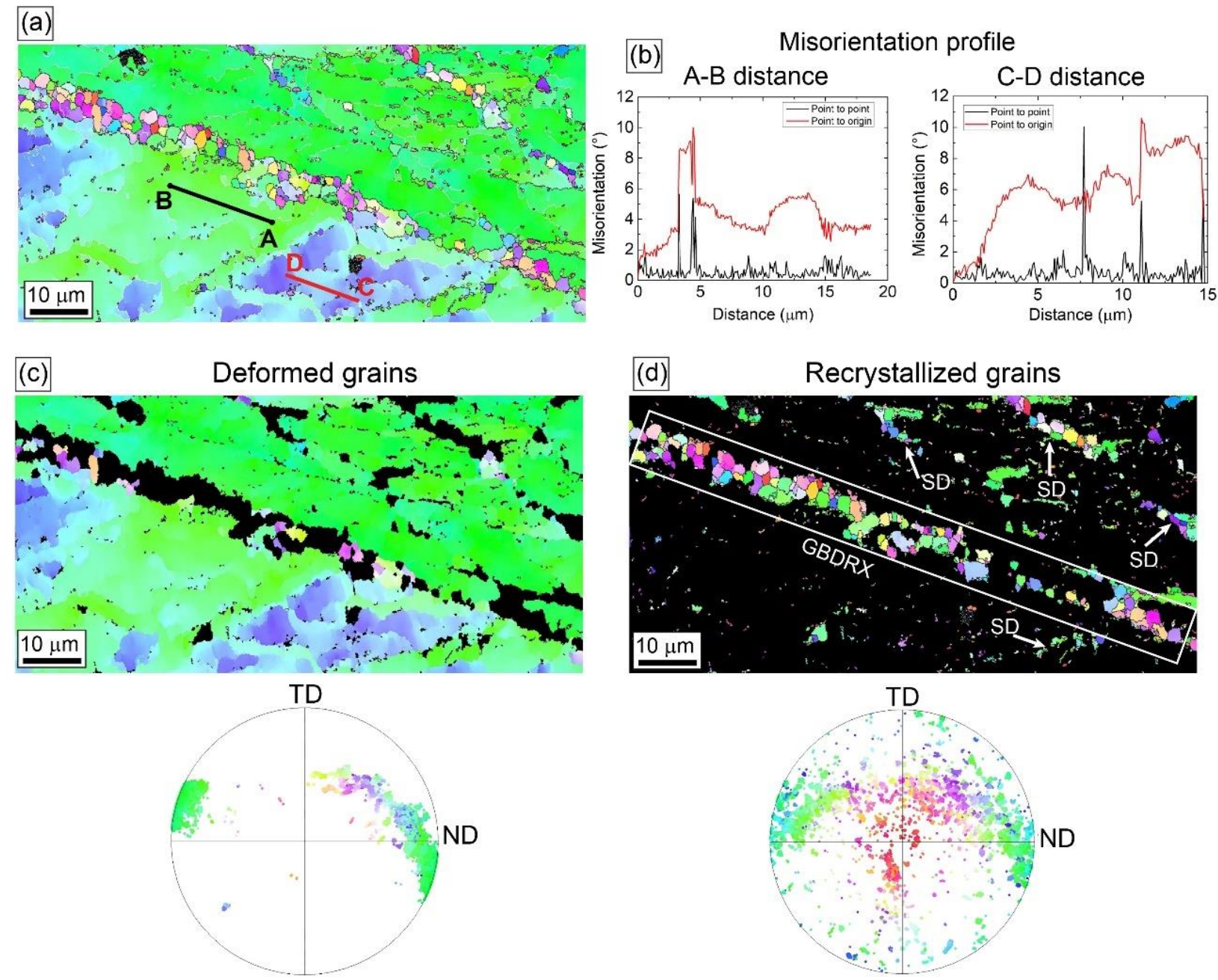

Figure 11: (a) ED-IPF map of a selected zone from the sample processed at $300{ }^{\circ} \mathrm{C}$ for 2 passes, (b) misorientation angle profile along $\mathrm{AB}$ and $\mathrm{CD}$ lines, (c, d) ED-IPF map and the corresponding $\{0002\}$ pole figure showing the orientations of the deformed and recrystallized grains, respectively.

In the case of ECAP processing at $350{ }^{\circ} \mathrm{C}$, the identification of the DRX mechanism was not possible since the recrystallized grains were already formed soon after 1 pass and even undergo grain growth after 4 passes. However, based on literature reports, it is believed that the DDRX mechanism is the main responsible for grain refinement at high deformation temperature. It has been found that the effect of RE solute drag is limited against the high mobility of grain boundaries at high deformation temperature which allow the predominance of DDRX on GBBDRX $[82,83]$.

The rapid DRX and the occurrence of grain growth cause the decrease of the microhardness value of the samples processed at $350{ }^{\circ} \mathrm{C}$ compared to those processed at $300{ }^{\circ} \mathrm{C}$ 
as demonstrated in Figure 12a. The Hv value increases from $37 \mathrm{Hv}$ at the initial state to $51 \mathrm{Hv}$ and $46 \mathrm{Hv}$ after 1 pass at 300 and $350{ }^{\circ} \mathrm{C}$, respectively. The $\mathrm{Hv}$ values continued to increase with the increasing number of ECAP passes to reach a value of 64 and $55 \mathrm{Hv}$ after 4 passes at 300 and $350{ }^{\circ} \mathrm{C}$, respectively. The increase of $\mathrm{Hv}$ values is a evident consequence of the increase of dislocation density and grain refinement.
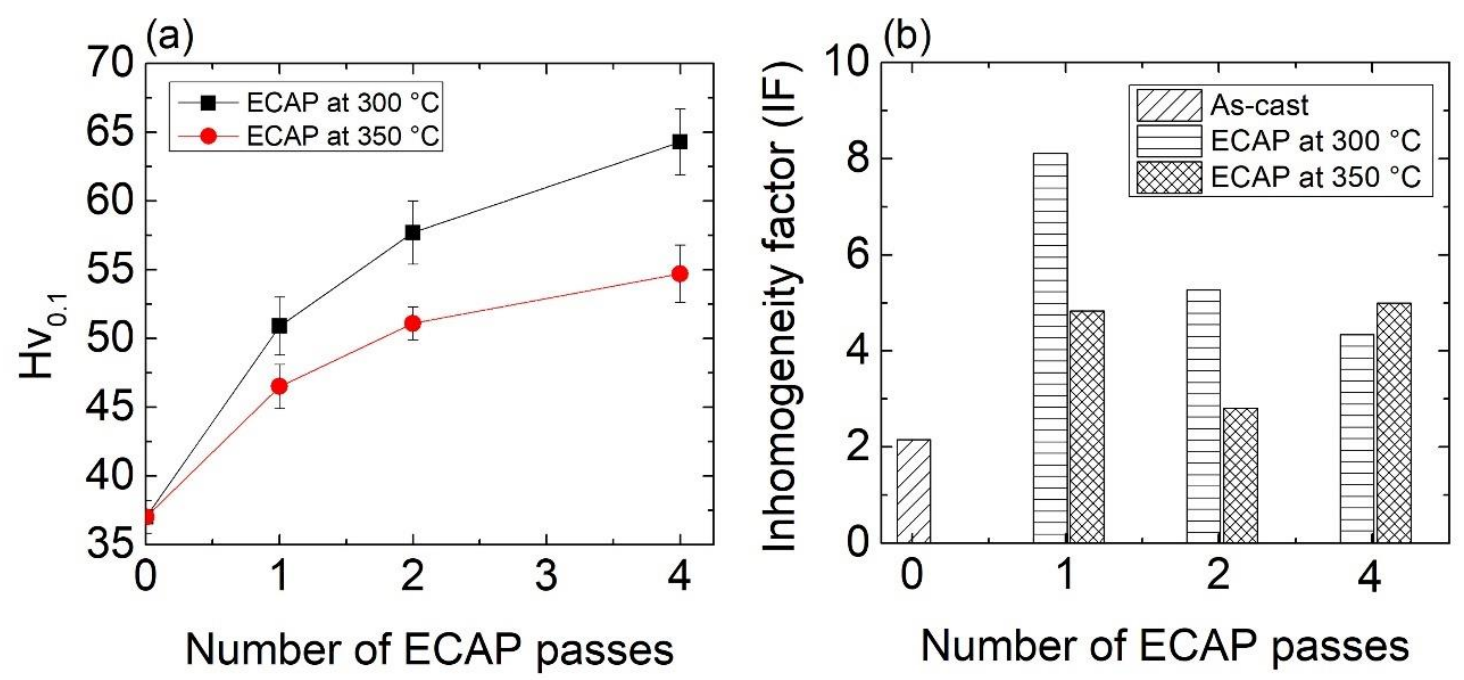

Figure 12: Evolution of (a) microhardness and (b) inhomogeneity factor as a function of the number of ECAP passes of $\mathrm{Mg}-0.3 \mathrm{Ce}$ processed at 300 and $350{ }^{\circ} \mathrm{C}$, respectively.

The deformation inhomogeneity during the deformation processing can be estimated by the inhomogeneity factor (IF) using the following equation [84]:

$$
I F=\frac{\sqrt{\sum_{i=1}^{n}\left(H v_{i}-H v_{\text {ave }}\right)^{2} / n-1}}{H v_{\text {ave }}} \times 100
$$

where $n$ is the number of microhardness measurements on each sample, Hvave the average microhardness value, and $\mathrm{Hv}_{\mathrm{i}}$ the microhardness value of $\mathrm{i}^{\text {th }}$ measurement.

The evolution of IF as a function of the number of ECAP passes of the present $\mathrm{Mg}$ $0.3 \mathrm{Ce}$ alloy at both deformation temperatures is shown in Figure 12b. It is believed that a microstructure with high homogeneity distribution of mechanical properties exhibits less IF value [84]. As can be seen the IF of the Mg-0.3Ce alloy increases after processing for 1 pass mostly due to the strain hardening (generation of deformation features such as dislocation density) which generated the inhomogeneity of the microstructure and mechanical properties. 
However, the IF of sample processed at $300{ }^{\circ} \mathrm{C}$ is 2 times higher than the one of the specimen processed at $350^{\circ} \mathrm{C}$ probably due to dynamic precipitation as shown in Figure 3, which causes an extra strain hardening as obstacles to the dislocation movement. In the case of processing at $300{ }^{\circ} \mathrm{C}$, the IF value continuously decreases with the increasing number of ECAP passes applying the enhancement in deformation homogeneity due to the grain refinement. Several investigations have reported similar trends of the IF against increasing strain during SPD processing [85-87]. In contrast, in the case of processing at $350{ }^{\circ} \mathrm{C}$ the IF first decreases after 2 passes and then increases again after 4 passes. These results indicates that samples processed at higher temperatures exhibit a more homogenous microstructure except at a high strain level (4 passes) where the grain growth seems to cause the increase in the inhomogeneity of the mechanical properties.

\subsection{Texture development after ECAP processing}

The texture evolution of the deformed and recrystallized grains as a function of the number of ECAP passes for both deformation temperatures is presented in Figure 13 in terms of recalculated $\{0002\}$ pole figures. It is worth noting that the initial texture was not measured because of the large grains of the as-cast alloy. However, all processed samples are considered having the same initial texture. The main ideal ECAP texture components and fibers for HCP materials and a $\Phi=90^{\circ}$ die are listed in Table 1 and also illustrated in Figure 13. The ECAP texture components are derived from those in simple shear $\left(\varphi_{1}, \Phi, \varphi_{2}\right)$ by undergoing an additional rotation of $\Phi / 2$ to $\varphi_{1}:\left(\varphi_{1}+\Phi / 2, \Phi, \varphi_{2}\right)[88]$.

It must be noted that the texture measurement was obtained from EBSD scans. Nevertheless, it has been demonstrated that the EBSD measurement gives a satisfying texture evolution in comparison with X-ray and neutron diffraction measurements for ECAP processed Mg-based alloys even with a limited EBSD scan size [6, 26].

In the case of samples processed at $300{ }^{\circ} \mathrm{C}$, the deformed grains developed soon a partial P-fiber after 1 ECAP pass with a maximum located at $\mathrm{P}_{1}\left(200^{\circ}, 90^{\circ}, 0^{\circ}\right)$ and strong orientation named $\mathrm{C}\left(60^{\circ}, 45^{\circ}, 30^{\circ}\right)$ located between the $\mathrm{C}_{1}$ and $\mathrm{B}$ fibers (Figure 13a). This orientation has been reported in several papers as basal texture (B-fiber) rotated about $40-45^{\circ}$ towards the ED [4, 26-28]. This component is formed by shear-induced rotation of grains and mostly due to the activation of the <a> basal slip system [27]. It was shown that the type of deformation modes can be figured out by texture measurement, i.e. pole figure [89]. The recrystallized grains seem to develop a typical B-fiber and $\mathrm{C}_{1}$-fiber (Figure 13b). After 2 passes 
a different texture was formed where a Y-fiber and partial P-fiber with a maximum located at $\mathrm{P}_{2}\left(20^{\circ}, 80^{\circ}, 0^{\circ}\right)$ component can be noticed. Additionally, the $\mathrm{C}\left(60^{\circ}, 45^{\circ}, 30^{\circ}\right)$ component is formed in the recrystallized grains as shown in Figure 13d. The $\mathrm{C}$ component became dominant after ECAP processing at $300{ }^{\circ} \mathrm{C}$ for 4 passes in the deformed and recrystallized grains (Figures $13 \mathrm{c}$ and $\mathrm{f}$ ). The domination of such texture has been largely reported in ECAP processed $\mathrm{Mg}$ based alloys [4, 7, 23-28].

Apparently, processing at $350{ }^{\circ} \mathrm{C}$ led to the development of different textures. The $\mathrm{C}$ and $\mathrm{P}_{2}$ components were formed soon after 1 pass in the deformed grains, while the $\mathrm{P}_{2}$ component seem to be replaced by the $\mathrm{C}_{1}$-fiber in the recrystallized grains (Figure 13j). The domination of the $\mathrm{C}$ component after 4 passes at $300{ }^{\circ} \mathrm{C}$ and its rapid formation at $350{ }^{\circ} \mathrm{C}$ after 1 pass may confirm the domination of the GBBDRX mechanism in these samples since it is believed that this mechanism strengthens the basal texture by limiting the pyramidal slip [75].

However, the domination of the P-fiber is clear in the deformed and recrystallized grains of the sample processed at 2 ECAP passes (Figures $13 \mathrm{~h}$ and $\mathrm{k}$ ). It is worth mentioning that the sample processed for 4 passes at $350{ }^{\circ} \mathrm{C}$ exhibits a completely different texture than that processed at $300{ }^{\circ} \mathrm{C}$ where a new component located at $\mathrm{S}\left(80^{\circ}, 90^{\circ}, 0^{\circ}\right)$ in which some grains have their $<0001>$ parallel to TD is developed in deformed and recrystallized grains. Similar texture formation has been described in LAE442 (Mg-4Li-3.5Al-1.3Ce, wt.\%) and WN43 (Mg-4Y-3Nd, wt.\%) alloys processed by ECAP up to 8 passes using route $B c[6,12]$. Accordingly, the origin of the formation of the P-fiber and <0001> // TD components was explained by the massive activation of the $\langle\mathrm{c}+\mathrm{a}\rangle$ pyramidal and prismatic slip systems, respectively $[6,12]$. However, it is well known that the activation of $\langle\mathrm{c}+\mathrm{a}\rangle$ pyramidal slip system needs more energy than the prismatic slip and hence the prismatic slip system is expected to be activated before the $\langle\mathrm{c}+\mathrm{a}\rangle$ pyramidal slip. Based on the present texture evolution the $<0001>/ / \mathrm{TD}$ component was formed only after 4 passes at $350{ }^{\circ} \mathrm{C}$, while the Pfiber was formed much earlier. Thus, the prismatic and $\langle c+a\rangle$ pyramidal slip systems could not be the origin of such texture formation. 
ECAP at $300^{\circ} \mathrm{C}$

$\mathrm{N}=1$

Deformed grains

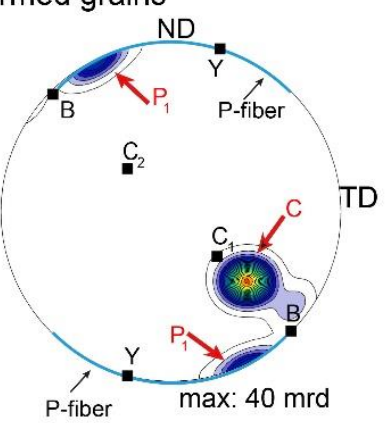

Recrystallized grains
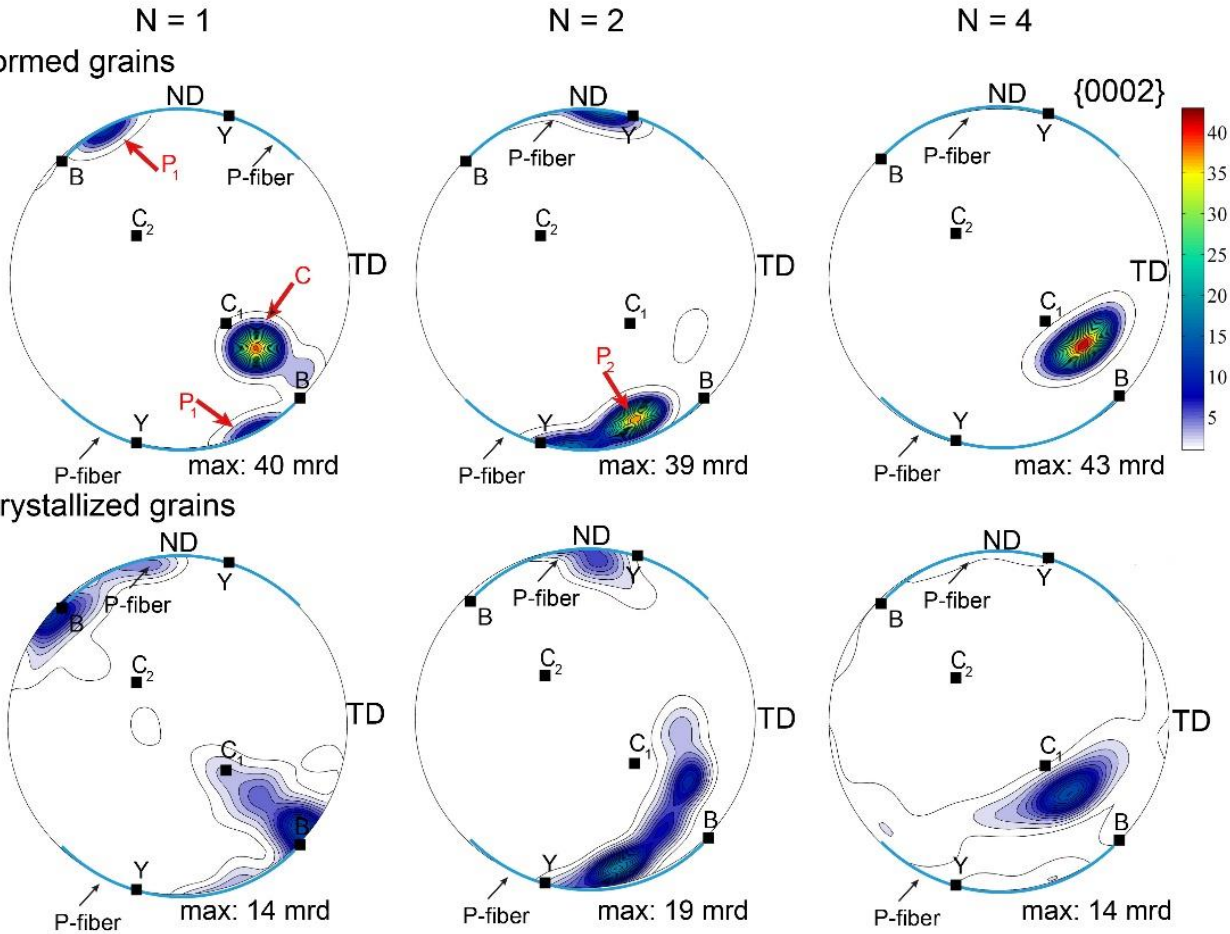

\section{ECAP at $350^{\circ} \mathrm{C}$}

Deformed grains
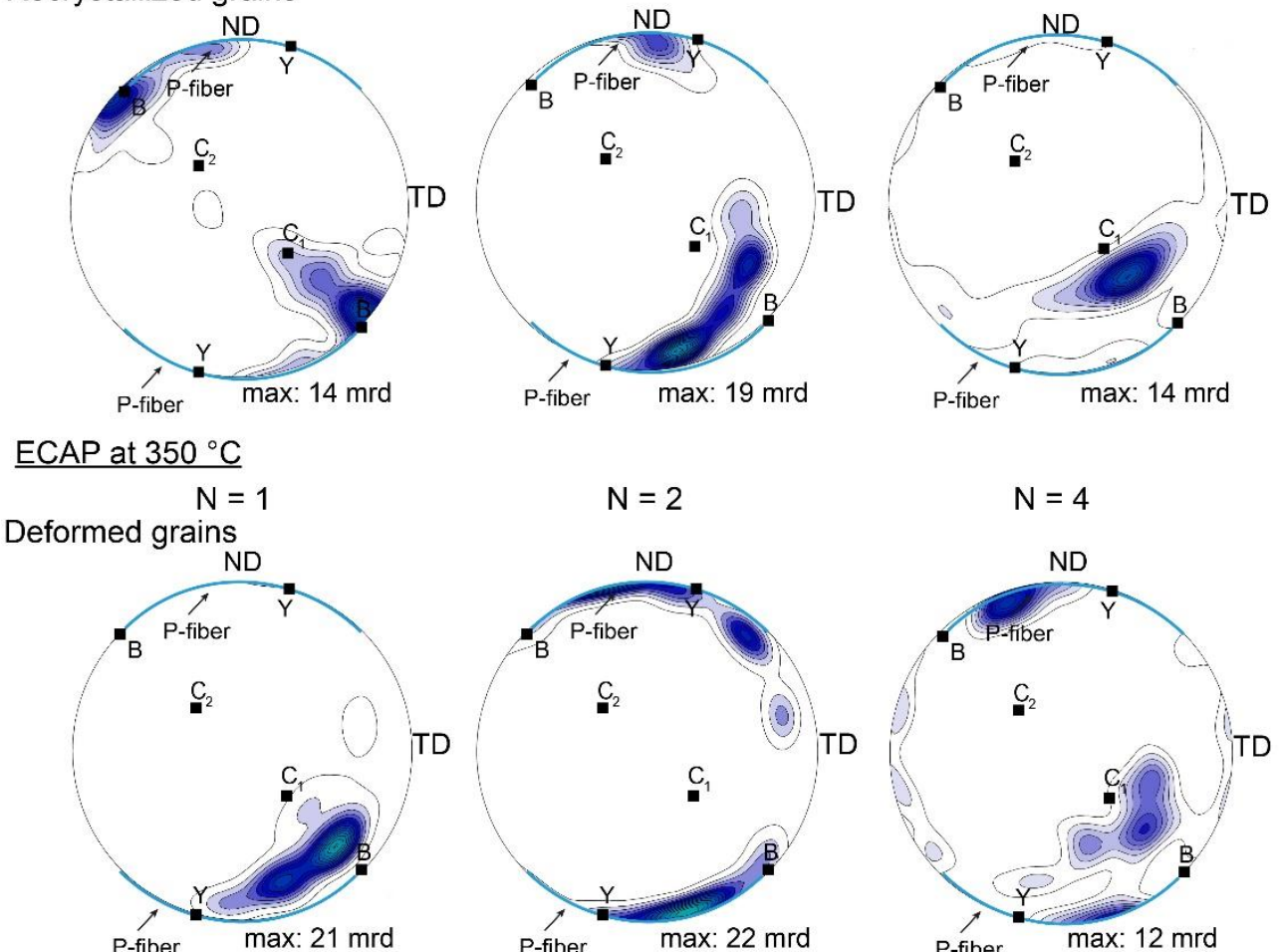

Recrystallized grains
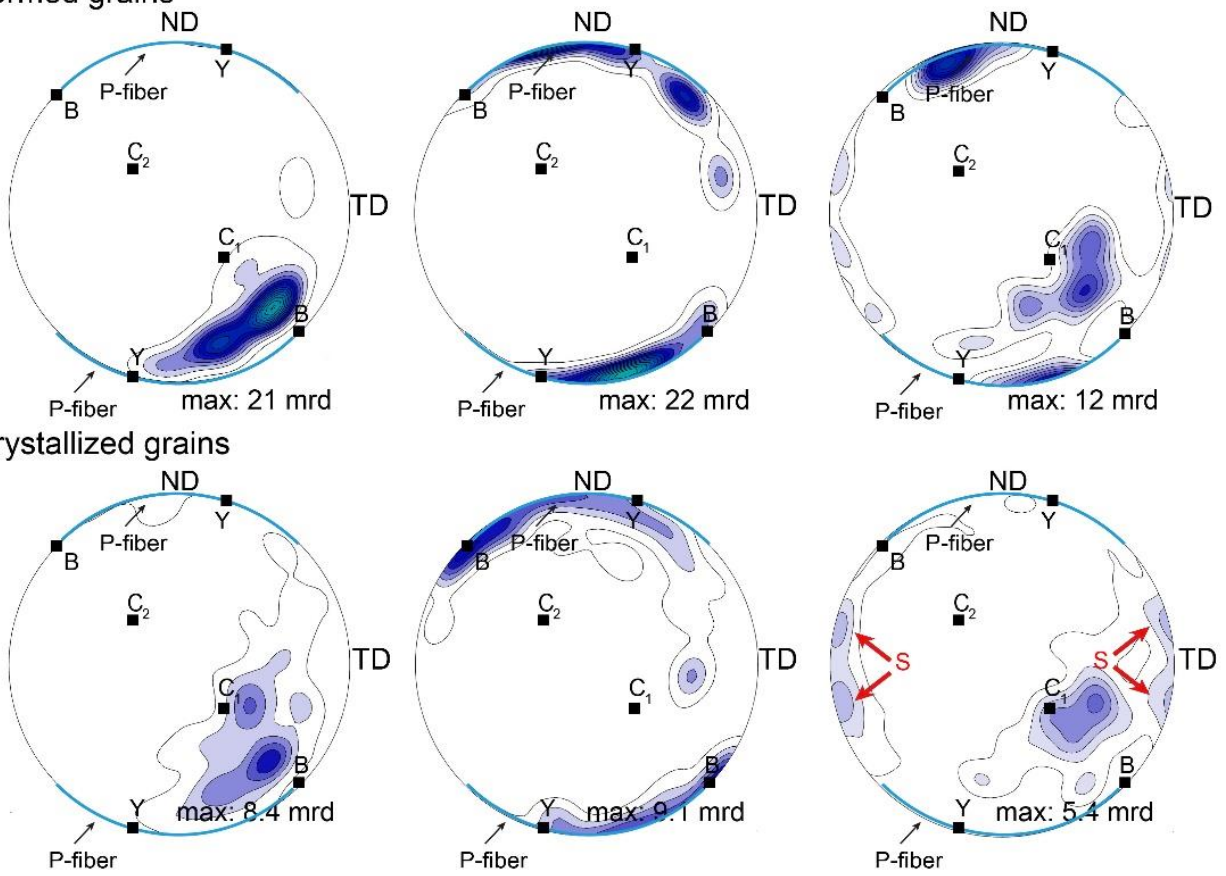

Figure 13: Recalculated $\{0002\}$ pole figures of deformed and recrystallized grains of $\mathrm{Mg}$ $0.3 \mathrm{Ce}$ alloy processed at 300 and $350{ }^{\circ} \mathrm{C}$ for 1,2 and 4 passes, respectevely. 
The instability of the texture with the increasing number of ECAP passes result from the sample rotation between ECAP passes (route $B_{C}$ ) which causes orthogonal changes in the strain path after every pass [90]. Also, the persistence and the stability of shear texture components strongly depend on the activation of different slip and twinning systems. For example, the presence of the $\mathrm{B}, \mathrm{P}$, and $\mathrm{Y}$ fibers corresponds with the high activation of the $<\mathrm{a}>$ basal slip system while the activation of $\langle\mathrm{c}+\mathrm{a}\rangle$ pyramidal slip system leads to the formation of $\mathrm{C}_{1}$ and $\mathrm{C}_{2}$ fibers [91]. Despite the similarity of DRX fraction in samples after 4 ECAP passes at both conditions, a clear different texture evolution can be observed.

Table 1. Position of ideal ECAP shear texture components with a $\Phi=90^{\circ}$ die for HCP materials projected in the TD-ND plane [88].

\begin{tabular}{ll}
\hline Notation & $\begin{array}{l}\text { Euler angle } \\
\left(\varphi_{1}, \Phi, \varphi_{2}\right)\end{array}$ \\
\hline B-fiber & $\left(45^{\circ}, 90^{\circ}, 0-60^{\circ}\right)$ \\
\hline P-fiber & $\left(125-225^{\circ}, 90^{\circ}, 0^{\circ}\right)$ \\
\hline Y-fiber & $\left(345^{\circ}, 90^{\circ}, 0-60^{\circ}\right)$ \\
\hline $\mathrm{C}_{1}$-fiber & $\left(45^{\circ}, 30^{\circ}, 0-60^{\circ}\right)$ \\
\hline $\mathrm{C}_{2}$-fiber & $\left(225^{\circ}, 30^{\circ}, 0-60^{\circ}\right)$ \\
\hline
\end{tabular}

The occurrence of grain growth in samples processed at $350{ }^{\circ} \mathrm{C}$ could be a plausible explanation for the texture modification. The development of recrystallization texture is related to the oriented nucleation and/or the oriented growth theory [92]. The oriented nucleation theory proposes that the formation of specific orientation remained stable during subsequent grain growth, while in the oriented growth theory, the grain orientation stability depends on the grain boundary mobility [92]. In the present study, the texture was typical from that reported for large Mg-based alloys (sharp C component) when the recrystallized grains were small (sample processed at $300{ }^{\circ} \mathrm{C}$ ). Increasing the recrystallized grains size caused the formation of new orientations not only in the recrystallized grains but in the deformed grains as well (sample processed at $350^{\circ} \mathrm{C}$ ). It can be concluded that the preferred grain growth is responsible for the texture modification between samples processed at 300 and $350{ }^{\circ} \mathrm{C}$. Besides, it is well known now that the addition of RE elements can significantly change the texture of Mg-based alloys during deformation and subsequent annealing by weakening the texture or formation of new orientations $[30,93]$. 
The recrystallized and deformed textures seem different in samples processed at $300{ }^{\circ} \mathrm{C}$ when the DRX mechanisms were distinguished in the early stages of deformation. However, with increasing strain and further increasing fraction of DRX the recrystallized and deformed grains seem to have a similar texture which is a typical $\mathrm{C}$ texture. In contrast, at $350{ }^{\circ} \mathrm{C}$ where the typical $\mathrm{C}$ texture is rapidly formed after 1 pass due to the rapid DRX rate, the recrystallized and deformed grains exhibit similar texture evolution in the early stages of deformation. The similarity of deformed and recrystallized texture at high strain and low deformation temperature (4 passes at $300{ }^{\circ} \mathrm{C}$ ) and at intermediate strain and high deformation temperature ( 1 and 2 passes at $350{ }^{\circ} \mathrm{C}$ ) confirm the occurrence of GBBDRX mechanism [75]. With increasing strain up to 4 passes the recrystallized and deformed grains display different textures, and new texture components were developed indicating that grain growth plays a great role in the texture modification in Mg-RE alloys.

It will be interesting in the future to investigate the static recrystallization during subsequent annealing of the ECAP-processed $\mathrm{Mg}-0.3 \mathrm{Ce}$ alloy in order to explore deeply the effect of the preferred growth theory on the texture modifications in severely deformed $\mathrm{Mg}$ RE alloys.

\section{Conclusion}

- A Mg-0.3Ce alloy was successfully processed by ECAP through 4 passes at 300 and $350{ }^{\circ} \mathrm{C}$ using route $\mathrm{B}_{\mathrm{c}}$. The evolution of the microstructure, texture, and mechanical properties were investigated using EBSD and Vickers microhardness.

- The optimum deformation temperature for ECAP processing of the $\mathrm{Mg}-0.3 \mathrm{Ce}$ alloy is $300{ }^{\circ} \mathrm{C}$ since the formability was insufficient at lower temperatures $\left(150\right.$ and $\left.250{ }^{\circ} \mathrm{C}\right)$ and arger grain sizes were obtained at a higher temperature $\left(350{ }^{\circ} \mathrm{C}\right)$.

- Significant grain refinement was obtained after 4 passes due to DRX where the initial grain size decreases from $1 \mathrm{~mm}$ to 6.7 and $8.3 \mu \mathrm{m}$ after 4 passes at 300 and $350{ }^{\circ} \mathrm{C}$, respectively.

- EBSD maps of samples processed at $300{ }^{\circ} \mathrm{C}$ demonstrated that at low strain DRX occurred via TDRX and PSN mechanisms. With increasing strain, SD and GBDRX mechanisms dominate the DRX processing.

- The microhardness of the alloy increases with the increasing number of ECAP passes and decreasing deformation temperature. The IF value decreased with the increasing number of ECAP passes indicating a decrease in deformation inhomogeneity. Larger 
grain sizes caused the increase of deformation inhomogeneity during processing at a higher temperature.

- The texture evolution strongly depends on the strain, temperature deformation, and DRX mechanisms. Processing at $300{ }^{\circ} \mathrm{C}$ led to the gradual formation and domination of the $\mathrm{C}$ component with increasing strain, while processing at $350{ }^{\circ} \mathrm{C}$ led to the rapid formation of the $\mathrm{C}$ component at low strain and the formation of new components at high strain due to the grain growth.

\section{Acknowledgments}

Dr. Talal Al-Samman from Institute for Physical Metallurgy and Materials Physics, RWTH Aachen University, Germany is heartily acknowledged for providing the alloy. This investigation was partially supported by the PRFU national project under Grant Agreement No. B00L02UN280120180005.

\section{Data availability}

The raw/processed data required to reproduce these findings cannot be shared at this time as the data also forms part of an ongoing study.

Conflict of Interest: The authors declare that they have no conflict of interest.

\section{References}

[1] K.U. Kainer, Challenges for Implementation of Magnesium into More Applications, in: A. Singh, K. Solanki, M.V. Manuel, N.R. Neelameggham (Eds.), Magnesium Technology 2016, Springer International Publishing, Cham, 2016, pp. 5-6.

[2] M.H. Yoo, Slip, twinning, and fracture in hexagonal close-packed metals, Metallurgical Transactions A 12(3) (1981) 409-418.

[3] S. Biswas, S. Singh Dhinwal, S. Suwas, Room-temperature equal channel angular extrusion of pure magnesium, Acta Materialia 58(9) (2010) 3247-3261.

[4] F. Zhang, K.-x. Zhang, C.-w. Tan, X.-d. Yu, H.-l. Ma, F.-c. Wang, H.-n. Cai, Microstructure and mechanical properties of $\mathrm{Mg}-\mathrm{Gd}-\mathrm{Y}-\mathrm{Zr}$ alloy processed by equal channel angular pressing, Transactions of Nonferrous Metals Society of China 21(10) (2011) 2140-2146. 
[5] P. Minárik, R. Král, J. Pešička, S. Daniš, M. Janeček, Microstructure characterization of LAE442 magnesium alloy processed by extrusion and ECAP, Materials Characterization 112 (2016) 1-10.

[6] P. Minárik, R. Král, J. Č́žžek, F. Chmelík, Effect of different c/a ratio on the microstructure and mechanical properties in magnesium alloys processed by ECAP, Acta Materialia 107 (2016) 83-95.

[7] R.K. Sabat, A.P. Brahme, R.K. Mishra, K. Inal, S. Suwas, Ductility enhancement in Mg0.2\%Ce alloys, Acta Materialia 161 (2018) 246-257.

[8] R.K. Sabat, P.K. Samal, M. Ahamed S, Effect of strain path on the evolution of microstructure, texture and tensile properties of WE43 alloy, Materials Science and Engineering: A 715 (2018) 348-358.

[9] P. Bhagat Singh, R.K. Sabat, S. Kumaran, S. Suwas, Effect of Aluminum Addition on the Evolution of Microstructure, Crystallographic Texture and Mechanical Properties of Single Phase Hexagonal Close Packed Mg-Li Alloys, Journal of Materials Engineering and Performance 27(2) (2018) 864-874.

[10] D. Panda, R.K. Sabat, S. Suwas, V.D. Hiwarkar, S.K. Sahoo, Texture weakening in pure magnesium during grain growth, Philosophical Magazine 99(11) (2019) 1362-1385.

[11] Y. Ma, F.-Y. Han, C. Liu, M.-Z. Li, Microstructure, Texture Evolution, and Mechanical Properties of ECAP-Processed ZAT522 Magnesium Alloy, Acta Metallurgica Sinica (English Letters) 33(2) (2020) 233-242.

[12] P. Minárik, M. Zemková, J. Veselý, J. Bohlen, M. Knapek, R. Král, The effect of Zr on dynamic recrystallization during ECAP processing of Mg-Y-RE alloys, Materials Characterization (2021) 111033.

[13] J. Humphreys, G.S. Rohrer, A. Rollett, Chapter 7 - Recrystallization of Single-Phase Alloys, in: J. Humphreys, G.S. Rohrer, A. Rollett (Eds.), Recrystallization and Related Annealing Phenomena (Third Edition), Elsevier, Oxford, 2017, pp. 245-304.

[14] S. Seipp, M.F.X. Wagner, K. Hockauf, I. Schneider, L.W. Meyer, M. Hockauf, Microstructure, crystallographic texture and mechanical properties of the magnesium alloy AZ31B after different routes of thermo-mechanical processing, International Journal of Plasticity 35 (2012) 155-166.

[15] T. Krajňák, P. Minárik, J. Gubicza, K. Máthis, R. Kužel, M. Janeček, Influence of equal channel angular pressing routes on texture, microstructure and mechanical properties of extruded AX41 magnesium alloy, Materials Characterization 123 (2017) 282-293. 
[16] W.J. Kim, S.I. Hong, Y.S. Kim, S.H. Min, H.T. Jeong, J.D. Lee, Texture development and its effect on mechanical properties of an AZ61 Mg alloy fabricated by equal channel angular pressing, Acta Materialia 51(11) (2003) 3293-3307.

[17] J. Jiang, Y. Wang, J. Qu, Microstructure and mechanical properties of AZ61 alloys with large cross-sectional size fabricated by multi-pass ECAP, Materials Science and Engineering: A $560(2013) 473-480$.

[18] H. Liu, Z. Cheng, K. Yan, J. Yan, J. Bai, J. Jiang, A. Ma, Effect of Multi-Pass Equal Channel Angular Pressing on the Microstructure and Mechanical Properties of a Heterogeneous Mg88Y8Zn4 Alloy, Journal of Materials Science \& Technology 32(12) (2016) 1274-1281.

[19] M. Vishnoi, S. Senthil Murugan, A.N. Veerendra Kumar, T.G. Mamatha, Analysis of plastic deformation of A16063, Magnesium AZ91C and commercially used Titanium alloys using ECAP, Materials Today: Proceedings 25 (2020) 710-718.

[20] S.M. Arab, A. Akbarzadeh, The effect of Equal Channel Angular Pressing process on the microstructure of AZ31 Mg alloy strip shaped specimens, Journal of Magnesium and Alloys 1(2) (2013) 145-149.

[21] M. Furukawa, Z. Horita, M. Nemoto, T.G. Langdon, Review: Processing of metals by equal-channel angular pressing, Journal of Materials Science 36(12) (2001) 2835-2843.

[22] R.B. Figueiredo, T.G. Langdon, Principles of grain refinement in magnesium alloys processed by equal-channel angular pressing, Journal of Materials Science 44(17) (2009) 47584762.

[23] T. Liu, Y.D. Wang, S.D. Wu, R. Lin Peng, C.X. Huang, C.B. Jiang, S.X. Li, Textures and mechanical behavior of Mg-3.3\%Li alloy after ECAP, Scripta Materialia 51(11) (2004) 10571061.

[24] S.R. Agnew, J.A. Horton, T.M. Lillo, D.W. Brown, Enhanced ductility in strongly textured magnesium produced by equal channel angular processing, Scripta Materialia 50(3) (2004) 377-381.

[25] H.K. Lin, J.C. Huang, T.G. Langdon, Relationship between texture and low temperature superplasticity in an extruded AZ31 Mg alloy processed by ECAP, Materials Science and Engineering: A 402(1) (2005) 250-257.

[26] Y. Estrin, S.B. Yi, H.-G. Brokmeier, Z. Zúberová, S.C. Yoon, H.S. Kim, R.J. Hellmig, Microstructure, texture and mechanical properties of the magnesium alloy AZ31 processed by ECAP, International Journal of Materials Research 99(1) (2008) 50-55. 
[27] J. Müller, M. Janeček, S. Yi, J. Čížek, L. Wagner, Effect of equal channel angular pressing on microstructure, texture, and high-cycle fatigue performance of wrought magnesium alloys, International Journal of Materials Research 100(6) (2009) 838-842.

[28] M. Janeček, S. Yi, R. Král, J. Vrátná, K.U. Kainer, Texture and microstructure evolution in ultrafine-grained AZ31 processed by EX-ECAP, Journal of Materials Science 45(17) (2010) 4665-4671.

[29] P. Minárik, J. Veselý, R. Král, J. Bohlen, J. Kubásek, M. Janeček, J. Stráská, Exceptional mechanical properties of ultra-fine grain Mg-4Y-3RE alloy processed by ECAP, Materials Science and Engineering: A 708 (2017) 193-198.

[30] H. Azzeddine, D. Bradai, On the texture and grain growth in hot-deformed and annealed WE54 alloy, International Journal of Materials Research 103(11) (2012) 1351-1360.

[31] A. Imandoust, C.D. Barrett, T. Al-Samman, K.A. Inal, H. El Kadiri, A review on the effect of rare-earth elements on texture evolution during processing of magnesium alloys, Journal of Materials Science 52(1) (2017) 1-29.

[32] I.-H. Jung, M. Sanjari, J. Kim, S. Yue, Role of RE in the deformation and recrystallization of Mg alloy and a new alloy design concept for Mg-RE alloys, Scripta Materialia 102 (2015) $1-6$.

[33] I. Basu, T. Al-Samman, G. Gottstein, Shear band-related recrystallization and grain growth in two rolled magnesium-rare earth alloys, Materials Science and Engineering: A 579 (2013) 50-56.

[34] Y. Iwahashi, J. Wang, Z. Horita, M. Nemoto, T.G. Langdon, Principle of equal-channel angular pressing for the processing of ultra-fine grained materials, Scripta Materialia 35(2) (1996) 143-146.

[35] F. Bachmann, R. Hielscher, H. Schaeben, Texture Analysis with MTEX - Free and Open Source Software Toolbox, Solid State Phenomena 160 (2010) 63-68.

[36] D. Zhao, G. Li, P. Li, J. Zhou, K. Cheng, Y. Liu, Y. Yang, J. Duan, R. Ghomashchi, X. Wang, A comparative study on the microstructures and mechanical properties of the MgxCa/Mn/Ce alloys and pure Mg, Materials Science and Engineering: A 803 (2021) 140508.

[37] Y. Cubides, D. Zhao, L. Nash, D. Yadav, K. Xie, I. Karaman, H. Castaneda, Effects of dynamic recrystallization and strain-induced dynamic precipitation on the corrosion behavior of partially recrystallized Mg-9Al-1Zn alloys, Journal of Magnesium and Alloys 8(4) (2020) 1016-1037. 
[38] T.S. Srivatsan, E.J. Lavernia, The presence and consequences of precipitatefree zones in an aluminium-copper-lithium alloy, Journal of Materials Science 26(4) (1991) 940-950.

[39] B. Cai, B.L. Adams, T.W. Nelson, Relation between precipitate-free zone width and grain boundary type in 7075-T7 Al alloy, Acta Materialia 55(5) (2007) 1543-1553.

[40] T. Ogura, S. Hirosawa, A. Cerezo, T. Sato, Atom probe tomography of nanoscale microstructures within precipitate free zones in $\mathrm{Al}-\mathrm{Zn}-\mathrm{Mg}(-\mathrm{Ag})$ alloys, Acta Materialia 58(17) (2010) 5714-5723.

[41] T. Ogura, S. Hirosawa, T. Sato, Quantitative characterization of precipitate free zones in $\mathrm{Al}-\mathrm{Zn}-\mathrm{Mg}(-\mathrm{Ag})$ alloys by microchemical analysis and nanoindentation measurement, Science and Technology of Advanced Materials 5(4) (2004) 491-496.

[42] A. Tolley, D. Mitlin, V. Radmilovic, U. Dahmen, Transmission electron microscopy analysis of grain boundary precipitate-free-zones (PFZs) in an $\mathrm{AlCuSiGe}$ alloy, Materials Science and Engineering: A 412(1) (2005) 204-213.

[43] A. Zindal, J. Jain, R. Prasad, S.S. Singh, Effect of pre-strain and grain size on the evolution of precipitate free zones (PFZs) in a Mg-8Al-0.5Zn alloy, Materials Letters 201 (2017) 207210.

[44] Y. Zhang, W. Rong, Y. Wu, L. Peng, J.-F. Nie, N. Birbilis, A comparative study of the role of $\mathrm{Ag}$ in microstructures and mechanical properties of $\mathrm{Mg}-\mathrm{Gd}$ and $\mathrm{Mg}-\mathrm{Y}$ alloys, Materials Science and Engineering: A 731 (2018) 609-622.

[45] J.D. Embury, R.B. Nicholson, The nucleation of precipitates: The system Al-Zn-Mg, Acta Metallurgica 13(4) (1965) 403-417.

[46] G.W. Lorimer, R.B. Nicholson, Further results on the nucleation of precipitates in the AlZn-Mg system, Acta Metallurgica 14(8) (1966) 1009-1013.

[47] P.N.T. Unwin, G.W. Lorimer, R.B. Nicholson, The origin of the grain boundary precipitate free zone, Acta Metallurgica 17(11) (1969) 1363-1377.

[48] S.C. Jha, T.H. Sanders, M.A. Dayananda, Grain boundary precipitate free zones in Al-Li alloys, Acta Metallurgica 35(2) (1987) 473-482.

[49] K. Saito, H. Kaneki, TEM study of real precipitation behavior of an $\mathrm{Mg}-0.5$ at\%Ce agehardened alloy, Journal of Alloys and Compounds 574 (2013) 283-289.

[50] S. Khani, M.T. Salehi, H.R. Samim, M.R. Aboutalebi, H. Palkowski, The effect of severe plastic deformation on the microstructure and mechanical properties of as-cast AZ31, Iranian Journal of Materials Science \& Engineering 13(3) (2016) 29-38. 
[51] C.W. Su, L. Lu, M.O. Lai, A model for the grain refinement mechanism in equal channel angular pressing of $\mathrm{Mg}$ alloy from microstructural studies, Materials Science and Engineering: A 434(1) (2006) 227-236.

[52] M. Peron, P.C. Skaret, A. Fabrizi, A. Varone, R. Montanari, H.J. Roven, P. Ferro, F. Berto, J. Torgersen, The effect of Equal Channel Angular Pressing on the stress corrosion cracking susceptibility of AZ31 alloy in simulated body fluid, Journal of the Mechanical Behavior of Biomedical Materials 106 (2020) 103724.

[53] M. Avvari, N. S, M. Able, Microstructure evolution in AZ61 alloy processed by equal channel angular pressing, Advances in Mechanical Engineering 8(6) (2016) 1-9.

[54] L.B. Tong, J.H. Chu, W.T. Sun, Z.H. Jiang, D.N. Zou, S.F. Liu, S. Kamado, M.Y. Zheng, Development of a high-strength $\mathrm{Mg}$ alloy with superior ductility through a unique texture modification from equal channel angular pressing, Journal of Magnesium and Alloys (2020). [55] B. Li, B. Teng, G. Chen, Microstructure evolution and mechanical properties of Mg-GdY-Zn-Zr alloy during equal channel angular pressing, Materials Science and Engineering: A 744 (2019) 396-405.

[56] J.-H. Cho, A.D. Rollett, K.H. Oh, Determination of a mean orientation in electron backscatter diffraction measurements, Metallurgical and Materials Transactions A 36(12) (2005) 3427-3438.

[57] F. Guerza-Soualah, H. Azzeddine, T. Baudin, A.-L. Helbert, F. Brisset, D. Bradai, Microstructural and textural investigation of an $\mathrm{Mg}-\mathrm{Dy}$ alloy after hot plane strain compression, Journal of Magnesium and Alloys 8(4) (2020) 1198-1207.

[58] F. Guerza-Soualah, A. Hanna, H. Azzeddine, A.-L. Helbert, F. Brisset, T. Baudin, D. Bradai, The deformation and recrystallization behaviour of an Mg-Dy alloy processed by plane strain compression, Materials Today Communications 24 (2020) 101239.

[59] F. Abouhilou, A. Hanna, H. Azzeddine, D. Bradai, Microstructure and texture evolution of AZ31 Mg alloy after uniaxial compression and annealing, Journal of Magnesium and Alloys 7(1) (2019) 124-133.

[60] R.K. Mishra, A. Brahme, R.K. Sabat, L. Jin, K. Inal, Twinning and texture randomization in Mg and Mg-Ce alloys, International Journal of Plasticity 117 (2019) 157-172.

[61] J.P. Hadorn, K. Hantzsche, S. Yi, J. Bohlen, D. Letzig, J.A. Wollmershauser, S.R. Agnew, Role of Solute in the Texture Modification During Hot Deformation of Mg-Rare Earth Alloys, Metallurgical and Materials Transactions A 43(4) (2012) 1347-1362. 
[62] O.S. Sitdikov, E.V. Avtokratova, R.I. Babicheva, Effect of temperature on the formation of a microstructure upon equal-channel angular pressing of the Al-Mg-Sc 1570 alloy, The Physics of Metals and Metallography 110(2) (2010) 153-161.

[63] A. Yamashita, D. Yamaguchi, Z. Horita, T.G. Langdon, Influence of pressing temperature on microstructural development in equal-channel angular pressing, Materials Science and Engineering: A 287(1) (2000) 100-106.

[64] S.H. Kang, Y.S. Lee, J.H. Lee, Effect of grain refinement of magnesium alloy AZ31 by severe plastic deformation on material characteristics, Journal of Materials Processing Technology 201(1) (2008) 436-440.

[65] O. Sitdikov, R. Kaibyshev, T. Sakai, Dynamic Recrystallization Based on Twinning in Coarse-Grained Mg, Materials Science Forum 419-422 (2003) 521-526.

[66] H.Q. Sun, Y.N. Shi, M.X. Zhang, K. Lu, Plastic strain-induced grain refinement in the nanometer scale in a Mg alloy, Acta Materialia 55(3) (2007) 975-982.

[67] X. Li, P. Yang, L.N. Wang, L. Meng, F. Cui, Orientational analysis of static recrystallization at compression twins in a magnesium alloy AZ31, Materials Science and Engineering: A 517(1) (2009) 160-169.

[68] M.G. Jiang, H. Yan, R.S. Chen, Twinning, recrystallization and texture development during multi-directional impact forging in an AZ61 $\mathrm{Mg}$ alloy, Journal of Alloys and Compounds 650 (2015) 399-409.

[69] R.K. Sabat, D. Panda, S.K. Sahoo, Growth mechanism of extension twin variants during annealing of pure magnesium: An 'ex situ' electron backscattered diffraction investigation, Materials Characterization 126 (2017) 10-16.

[70] R.K. Sabat, S.K. Sahoo, An 'ex situ' electron backscattered diffraction study of nucleation and grain growth in pure magnesium, Materials \& Design 116 (2017) 65-76.

[71] T. Al-Samman, X. Li, S.G. Chowdhury, Orientation dependent slip and twinning during compression and tension of strongly textured magnesium AZ31 alloy, Materials Science and Engineering: A 527(15) (2010) 3450-3463.

[72] J.D. Robson, D.T. Henry, B. Davis, Particle effects on recrystallization in magnesiummanganese alloys: Particle-stimulated nucleation, Acta Materialia 57(9) (2009) 2739-2747.

[73] S.M. Fatemi, S. Aliyari, S.M. Miresmaeili, Dynamic precipitation and dynamic recrystallization during hot deformation of a solutionized WE43 magnesium alloy, Materials Science and Engineering: A 762 (2019) 138076. 
[74] M.R. Barnett, A. Sullivan, N. Stanford, N. Ross, A. Beer, Texture selection mechanisms in uniaxially extruded magnesium alloys, Scripta Materialia 63(7) (2010) 721-724.

[75] C. Xie, J.M. He, B.W. Zhu, X. Liu, J. Zhang, X.F. Wang, X.D. Shu, Q.H. Fang, Transition of dynamic recrystallization mechanisms of as-cast AZ31 Mg alloys during hot compression, International Journal of Plasticity 111 (2018) 211-233.

[76] L. Li, H. Li, W. Jiang, Z. Pan, Y. Wang, T. Wang, Thermal Deformation Behavior and Processing Maps of As-Homogenized Mg-5.8 Zn-0.5 Zr-1.0 Yb Alloy, JOM 71(6) (2019) 2033-2039.

[77] S.M. Fatemi-Varzaneh, A. Zarei-Hanzaki, H. Beladi, Dynamic recrystallization in AZ31 magnesium alloy, Materials Science and Engineering: A 456(1) (2007) 52-57.

[78] J. Zhang, B. Chen, C. Liu, An investigation of dynamic recrystallization behavior of ZK60-Er magnesium alloy, Materials Science and Engineering: A 612 (2014) 253-266.

[79] R. Ding, Z.X. Guo, Coupled quantitative simulation of microstructural evolution and plastic flow during dynamic recrystallization, Acta Materialia 49(16) (2001) 3163-3175.

[80] A. Galiyev, R. Kaibyshev, G. Gottstein, Correlation of plastic deformation and dynamic recrystallization in magnesium alloy ZK60, Acta Materialia 49(7) (2001) 1199-1207.

[81] H. Azzeddine, T. Baudin, A.-L. Helbert, F. Brisset, Y. Huang, M. Kawasaki, D. Bradai, T.G. Langdon, A stored energy analysis of grains with shear texture orientations in $\mathrm{Cu}-\mathrm{Ni}-\mathrm{Si}$ and Fe-Ni alloys processed by high-pressure torsion, Journal of Alloys and Compounds 864 (2021) 158142.

[82] N. Stanford, G. Sha, J.H. Xia, S.P. Ringer, M.R. Barnett, Solute segregation and texture modification in an extruded magnesium alloy containing gadolinium, Scripta Materialia 65(10) (2011) 919-921.

[83] M.G. Jiang, C. Xu, H. Yan, S.H. Lu, T. Nakata, C.S. Lao, R.S. Chen, S. Kamado, E.H. Han, Correlation between dynamic recrystallization and formation of rare earth texture in a Mg-Zn-Gd magnesium alloy during extrusion, Scientific Reports 8(1) (2018) 16800.

[84] E. Rafizadeh, A. Mani, M. Kazeminezhad, The effects of intermediate and post-annealing phenomena on the mechanical properties and microstructure of constrained groove pressed copper sheet, Materials Science and Engineering: A 515(1) (2009) 162-168.

[85] M. Alvand, M. Naseri, E. Borhani, H. Abdollah-Pour, Nano/ultrafine grained AA2024 alloy processed by accumulative roll bonding: A study of microstructure, deformation texture and mechanical properties, Journal of Alloys and Compounds 712 (2017) 517-525. 
[86] S.S. Satheesh Kumar, T. Raghu, Structural and mechanical behaviour of severe plastically deformed high purity aluminium sheets processed by constrained groove pressing technique, Materials \& Design 57 (2014) 114-120.

[87] F. Khodabakhshi, M. Kazeminezhad, A.H. Kokabi, Constrained groove pressing of low carbon steel: Nano-structure and mechanical properties, Materials Science and Engineering: A 527(16) (2010) 4043-4049.

[88] I.J. Beyerlein, L.S. Tóth, Texture evolution in equal-channel angular extrusion, Progress in Materials Science 54(4) (2009) 427-510.

[89] R.K. Sabat, M.V.S.S.D.S. Surya Pavan, D.S. Aakash, M. Kumar, S.K. Sahoo, Mechanism of texture and microstructure evolution during warm rolling of Ti-6Al-4V alloy, Philosophical Magazine 98(28) (2018) 2562-2581.

[90] S. Suwas, B. Beausir, L.S. Tóth, J.J. Fundenberger, G. Gottstein, Texture evolution in commercially pure titanium after warm equal channel angular extrusion, Acta Materialia 59(3) (2011) 1121-1133.

[91] B. Beausir, L.S. Tóth, K.W. Neale, Ideal orientations and persistence characteristics of hexagonal close packed crystals in simple shear, Acta Materialia 55(8) (2007) 2695-2705.

[92] R.D. Doherty, Nucleation and growth kinetics of different recrystallization texture components, Scripta Metallurgica 19(8) (1985) 927-930.

[93] N. Stanford, M.R. Barnett, The origin of "rare earth" texture development in extruded Mgbased alloys and its effect on tensile ductility, Materials Science and Engineering: A 496(1) (2008) 399-408. 